\title{
A BOREHOLE GAMMA-RAY SPECTROMETER FOR URANIUM EXPLORATION
}

\author{
Bendix Field Engineering Corporation \\ Grand Junction Operations \\ Crand Junction, Colorado 81501
}

May 1978

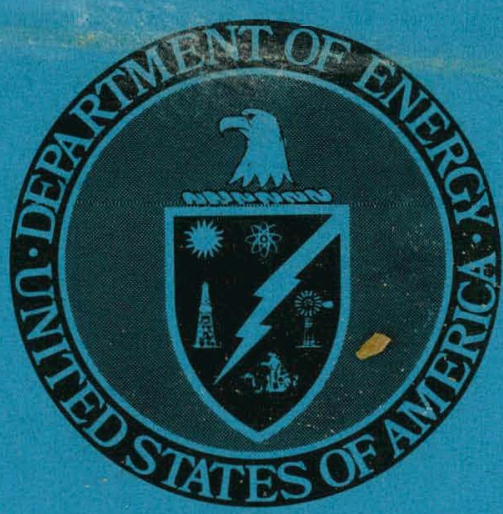

ISSUED BY THE U.S. DEPARTMENT OF ENERGY GRAND JUNCTION OFFICE UNDER CONTRACT NO. EY-76-C-13-1664 


\section{DISCLAIMER}

This report was prepared as an account of work sponsored by an agency of the United States Government. Neither the United States Government nor any agency Thereof, nor any of their employees, makes any warranty, express or implied, or assumes any legal liability or responsibility for the accuracy, completeness, or usefulness of any information, apparatus, product, or process disclosed, or represents that its use would not infringe privately owned rights. Reference herein to any specific commercial product, process, or service by trade name, trademark, manufacturer, or otherwise does not necessarily constitute or imply its endorsement, recommendation, or favoring by the United States Government or any agency thereof. The views and opinions of authors expressed herein do not necessarily state or reflect those of the United States Government or any agency thereof. 


\section{DISCLAIMER}

Portions of this document may be illegible in electronic image products. Images are produced from the best available original document. 
This report was prepared as an account of work sponsored by the United States Government. Neither the United States nor the United States Department of Energy, nor any of their employees, nor any of their contractors, subcontractors, or their employees, makes any warranty, express or implied, or assumes any legal liability or responsibility for the accuracy, completeness, or usefulness of any information, apparatus, product, or process disclosed, or represents that its use would not infringe privately owned rights. 


\title{
A BOREHOLE GAMMA-RAY SPECTROMETER FOR URANIUM EXPLORATION
}

David C. George

Hilton B. Evans

James W. Allen

B. Nathan Key

Daniel L. Ward

Mark A. Mathews

\author{
BENDIX FIELD ENGINEERING CORPORATION \\ Grand Junction Operations \\ Grand Junction, Colorado 81501
}

May 1978

\section{PREPARED FOR THE U.S. DEPARTMENT OF ENERGY}

UNDER CONTRACT NO. EY-76-C-13-1664 
$\underline{\text { Page }}$

SUMMARY

INTRODUCTION

SYSTEM DESCRIPTION AND PERFORMANCE CHARACTERISTICS 4

System Description $\quad 4$

Linear Pulse Processing Subsystem 4

Digital Recording Subsystem 9

System Performance Characteristics 9

Count Rates. $\quad 9$

Pulse Processing System Performance 11

Statistics and Logging Speed 13

Data Recording and Display 13

$\begin{array}{lll}\text { SYSTEM DESIGN } & \because & 17\end{array}$

Linear Pulse Processing Subsystem - Probe Section 17

$\begin{array}{ll}\text { Detectors and Photomultipliers } & 17\end{array}$

Preamplifier and Cable Driver $\quad 17$

Linear Pulse Processing Subsystem - Surface Section 21

Line Matching and Compensation 21

Lincar Pulse Mmplifiar 21

Automatic Gain Control Amplifier $\quad 24$

Single Channel Analyzers $\quad 24$

Ratemeter 26

Digital Data Recording Subsystem 26

$\begin{array}{ll}\text { Scalers and Timer } & 26\end{array}$

Digital ndnmeter 26

$\begin{array}{ll}\text { Controller } & 27\end{array}$ 


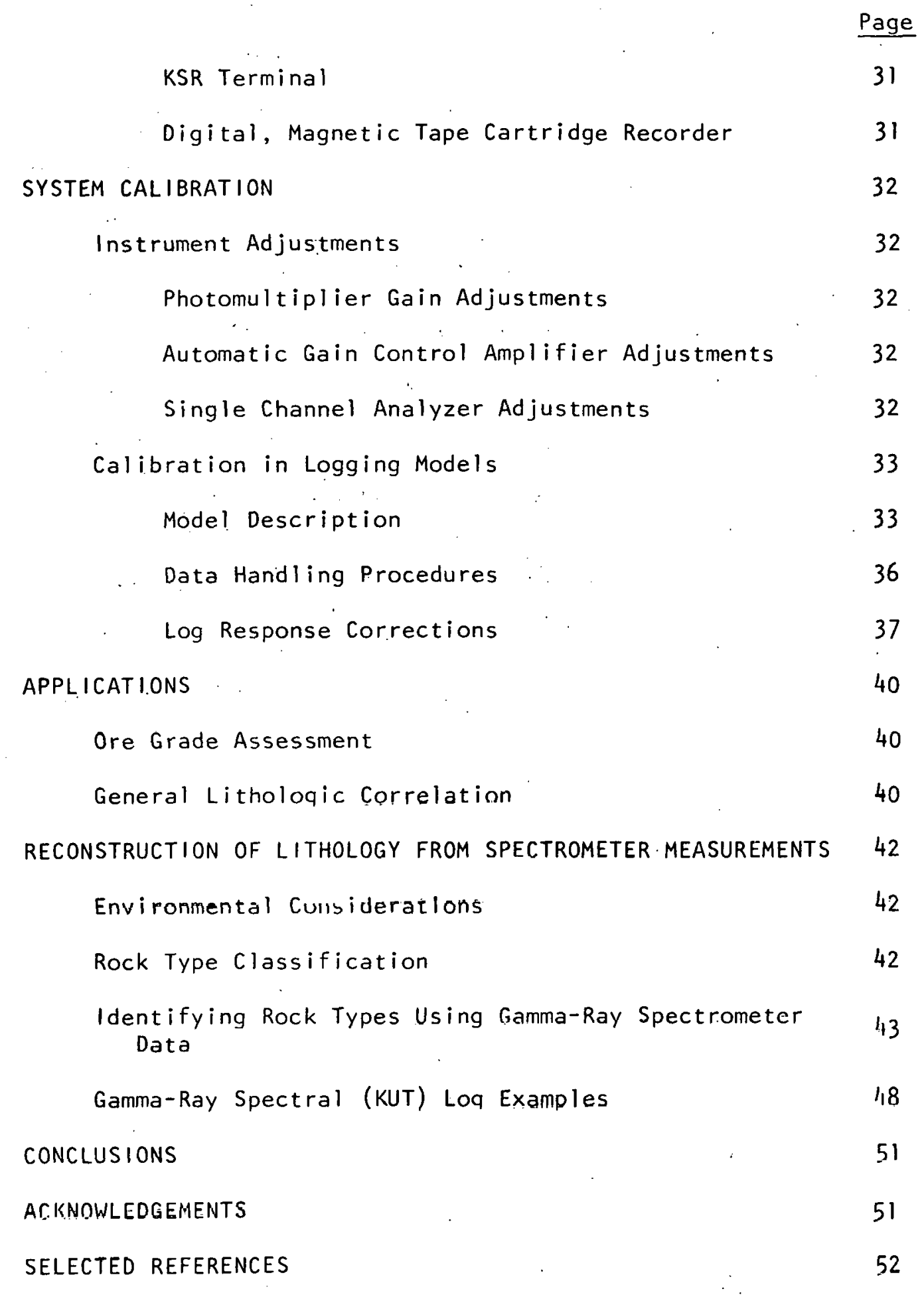


2 Typical Count Rates vs. Element Concentration 11

3 Typical System Resolution for Each Detector 13

4 Example Measurement Statistics $\quad 14$

5 Gamma-Ray Spectral Logging Model Concentrations 36

6 Some Average Background Values of U, Th, K, and Th/U 44 in Geologic Materials 


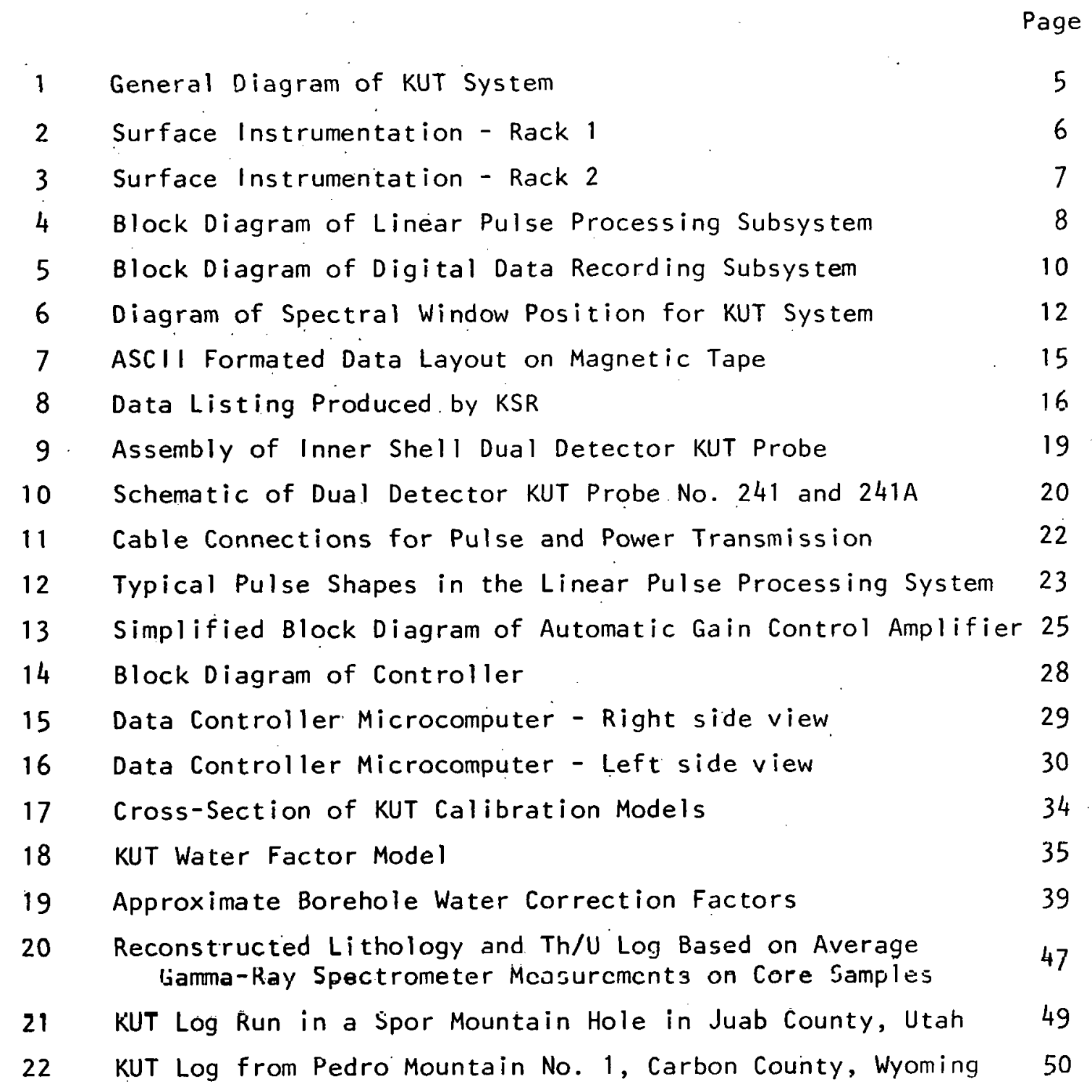




\section{SUMMARY}

This report describes a system designed to measure the concentrations of potassium, uranium, and thorium in boreholes. The system is divided into a linear pulse processing subsystem that consists of the probe and part of the surface electronics, and a digital recording subsystem. Gamma rays are detected in one of two $\mathrm{Nal}(\mathrm{T} \ell)$ crystals and the voltage pulses resulting from the scintillations in the crystal are linearly transmitted to the surface. The pulses are separated and counted in each of three channels corresponding to a window of energies in the gamma-ray spectrum. The resulting counts are then recorded on magnetic tape and optionally listed on a printer and strip-chart recorder. The recorded data are processed at a central computer where a graphic display of potassium, uranium, and thorium concentrations is constructed.

Some overall specifications for the system are:

$\begin{array}{cc}\text { Detector sizes -- } & 31 \text { and } 7.2 \text { cubic inches } \\ \text { Gain stabilization source - } & { }^{4} \mathrm{Mn}(835 \mathrm{KeV}) \\ \text { Typical count rates (large detector) } & \\ \text { K window } & 8.2 \mathrm{cps} / \mathrm{percent} \mathrm{K} \\ \text { U window } & 0.98 \mathrm{cps} / \mathrm{ppm} \mathrm{eU} \\ \text { Th window } & 0.22 \mathrm{cps} / \mathrm{ppm} \mathrm{eTh}\end{array}$

Photopeak resolution $\left(835 \mathrm{KeV}{ }^{34} \mathrm{Mn}\right)$-- About 8 percent

$\begin{array}{ll}\text { Typical logging speed -- } & 5 \text { feet per minute } \\ \text { Typical count interval -- } & 10 \text { seconds } \\ \text { Typical data point density -- } & 1 \text { data point per foot of borehole } \\ \text { Data storage medium -- } & \text { DC } 300 A \text { Cartridge Magnetic Tape } \\ \begin{array}{l}\text { Stored and listed data -- } \\ \text { (per data point) }\end{array} & \begin{array}{c}\text { Depth, measurement time, K-U-Th counts, } \\ \text { total counts, speed. }\end{array}\end{array}$


Following the detailed descriptions of the spectrometer system, a section is included which suggests some geologic/lithologic relationships where this system can be applied; some examples of log data obtained with this system are also included in this report. 


\section{INTRODUCTION}

Instrumentation and data analysis techniques have been devised to improve the evaluation accuracy of low-grade ore deposits that have become increasingly significant to the nation's uranium reserves. Observation of total gamma-ray activity is not sufficient to define and characterize the radioelement concentrations within low grade ore bodies. The total (or gross) gamma-ray activity shows that a mineralized zone is radioactive, but it does not define which element(s) are responsible for the radioactivity.

Potassium, uranium, and thorium comprise over 98 percent of the naturally occurring radioelements. Their relative concentrations can be determined with a gamma-ray spectrometer, which defines the activity of the gamma-ray emissions at specific energy levels characteristic of each element. Potassium is directly measured using the $1.46 \mathrm{Mev}$ gamma-ray energy emitted by potassium 40 . Uranium and thorium are indirectly measured from radioelements within their respective decay schemes; uranium is detected by observing the radiation of it's daughter product, bismuth $214(1.76 \mathrm{Mev})$, and thorium is defined by the gamma rays of thallium 208 (2.62 Mev).

A borehole logging system designed to measure the concentrations of the three primary naturally occurring, radioelements, $K, U$, and $T h$ is described in the inilial sections of this report; the system described is a second generation borehole spectrometer based on a development by Key and Eschliman, 1974. Some possible relationships between the KUT data obtained with a borehole spectrometer system and the types of rocks encountered in uranium exploration and exploitation are described in the balance of this report. 
SYSTEM DESCRIPTION

The basic spectrometer equipment consists of two distinct subsystems: a linear pulse processing unit containing both subsurface and surface sections, and a digital data recording and display unit. Figure 1 is a generalized block diagram of the total system. Figures 2 and 3 are photographs of all the surface instrumentation in the logging system. The arrows define the instruments which make up the spectrometer system.

LINEAR PULSE PROCESSING SUBSYSTEM

The probe (downhole) section of this subsystem, depicted in the upper half of Figure 4, includes two $\mathrm{Nal}$ ( $\mathrm{T} \ell$ ) detectors (31 and 7.2 cubic inches) with photomultiplier tubes and high-voltage power supplies, a charge sensitive preamplifier. a high frequency emphasis amplifier, and a line driver amplifier. The magnitude of the electrical charge in each pulse initially emitted from the photomultiplier has a linear relationship to the energy of the gamma ray generating the pulse. This linear relationship is maintained throughout the pulse processing system. The llnear pulse from the line driver amplifier is transmitted up a pair of conductors in the four conductor cable, and low voltage power is transmitted down the other pair. A control signal, transmitted down one of the signal wires, selects either the large or small detector.

In the surface (uphole) section of the linear pulse processing subsystem, depicted in the lower half of Figure 4, pulses are shaped and amplified after experiencing considerable degradation in transmission through the lngging cable. An automatic gain control amplifier (AGCA) stabilizes the spectrum of pulses by locking. onto the stabilization photopeak generated by an isotopic source mounted near the downhole detector. An oscilloscope, used to monitor system operation, is connected to the AGCA output (also see Stromswold and Meisner, 1978). 


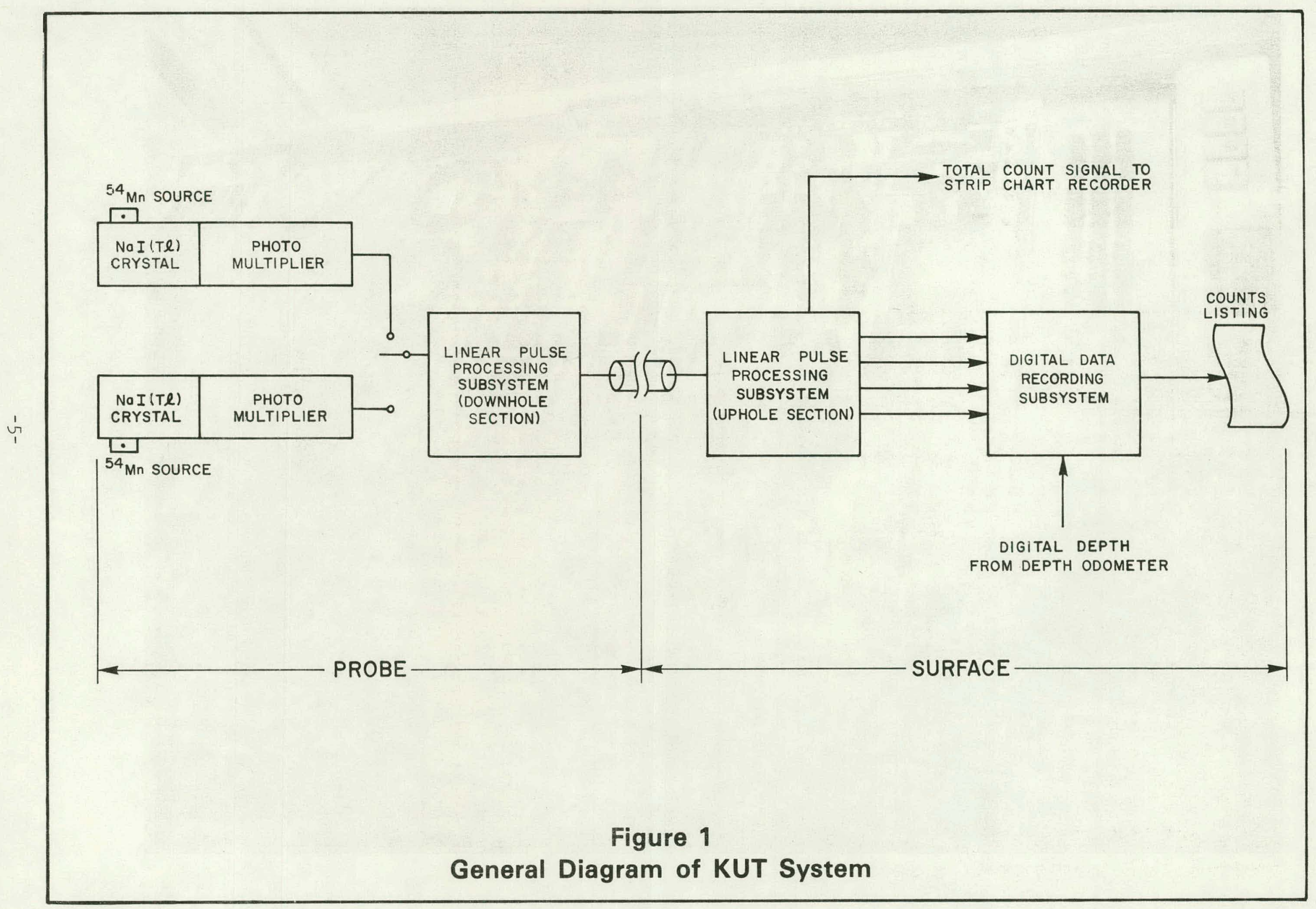




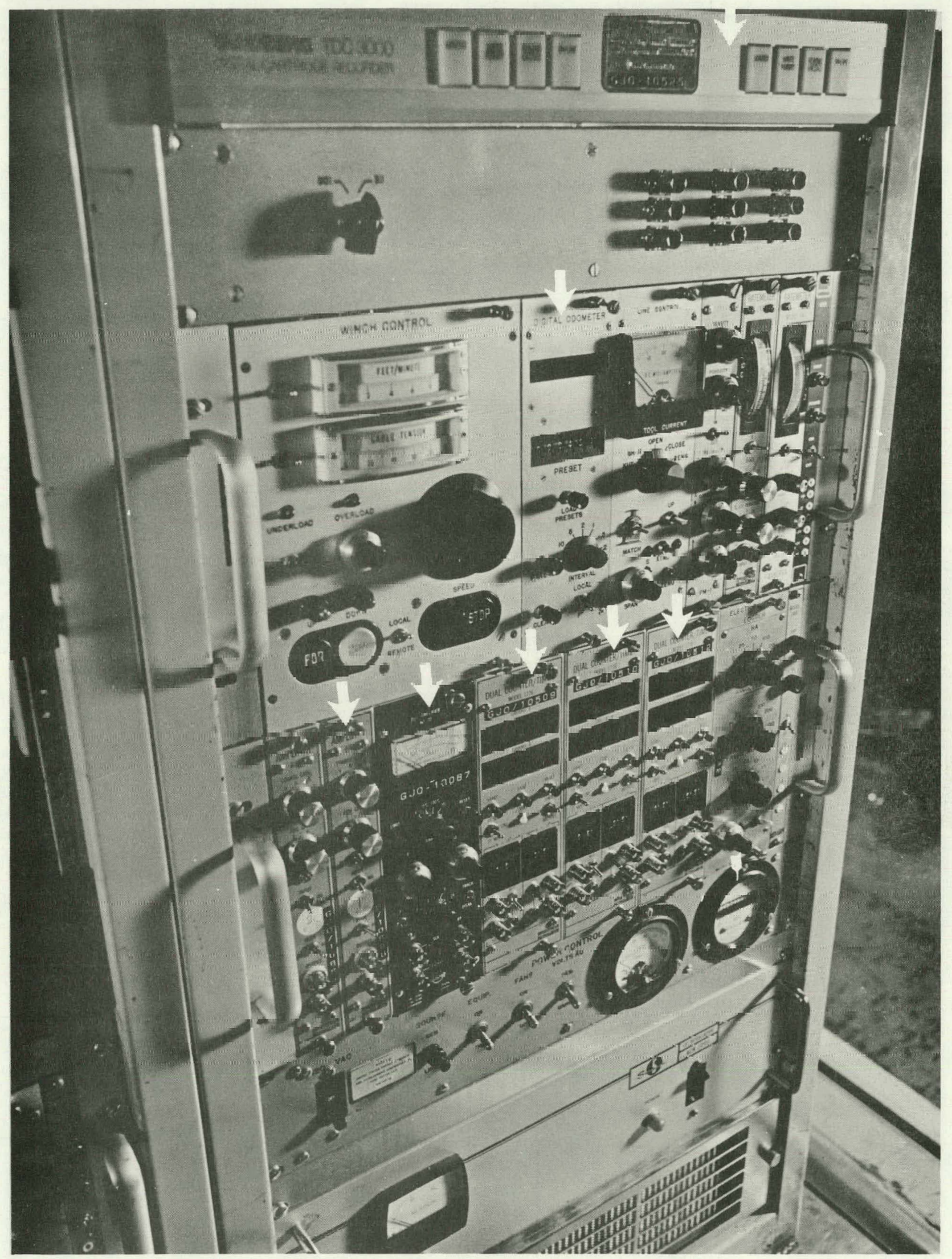

Figure 2

Surface Instrumentation-Rack 1 


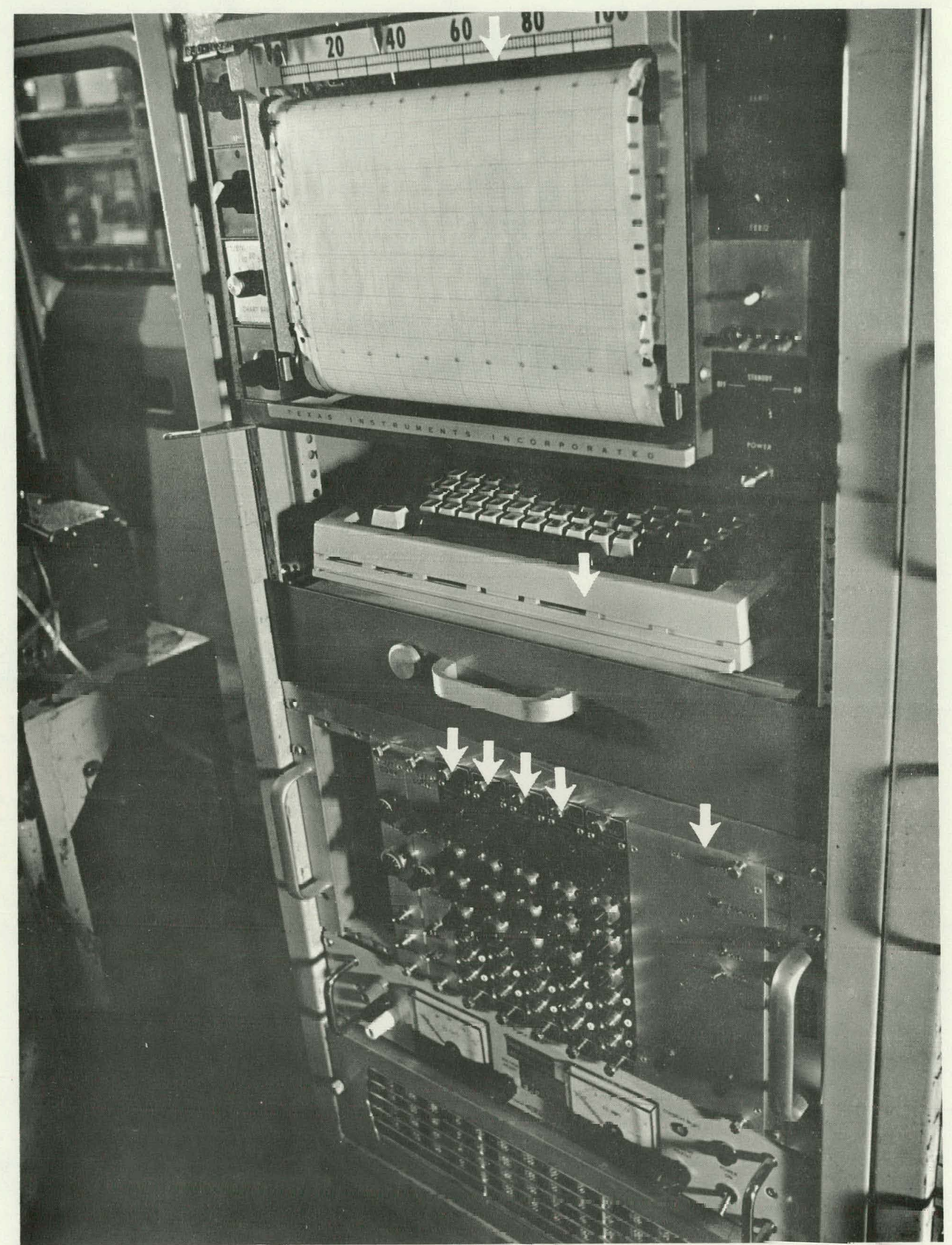

Figure 3

Surface Instrumentation-Rack 2 


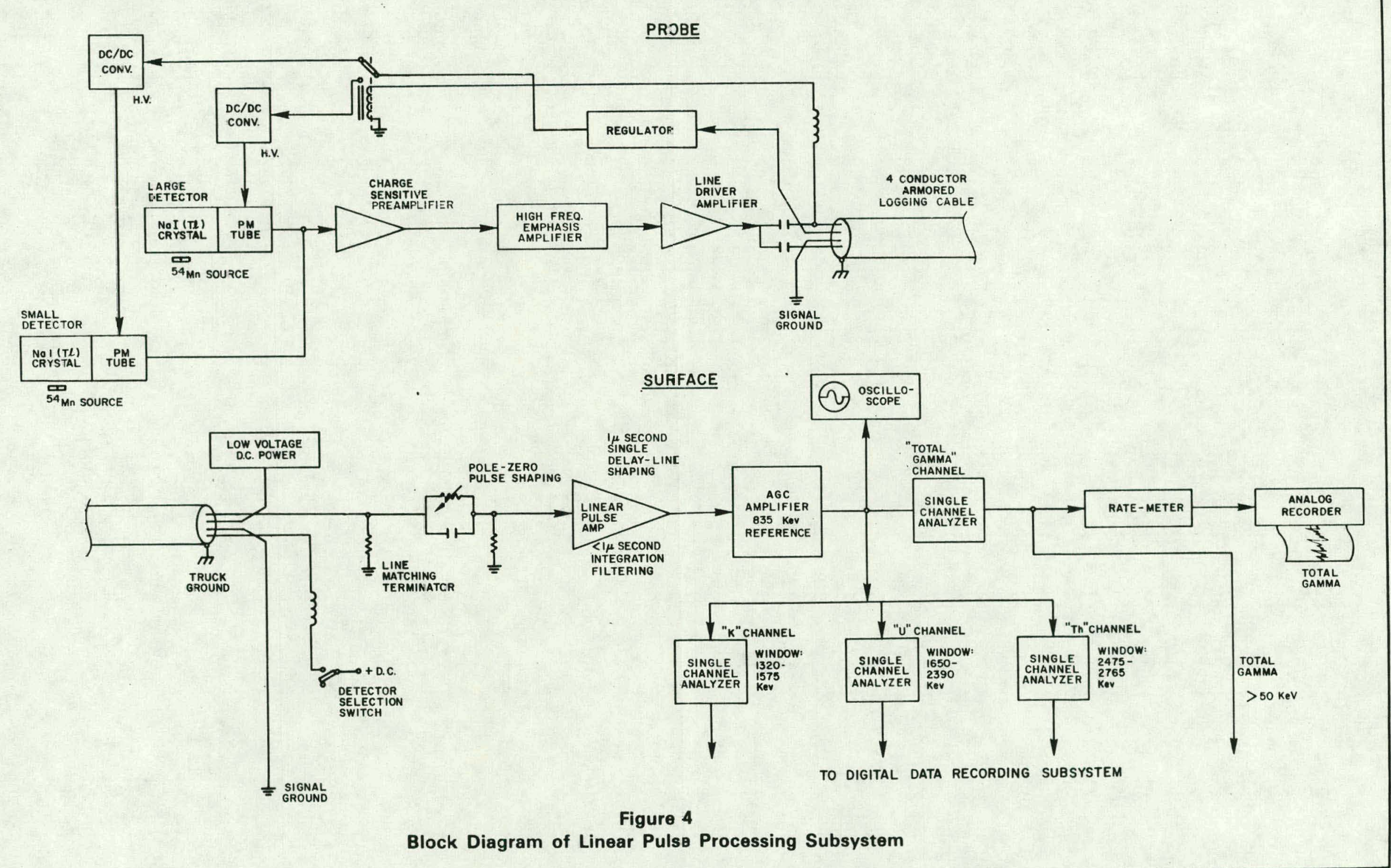


Linear pulses from the stabilizer are accepted at four single channel analyzers (SCA), each having pre-set thresholds. Three SCAs are adjusted to accept pulses from the three different regions of the spectrum representing potassium (K), uranium (U), and thorium (Th); a fourth, for total gamma, is adjusted to accept all pulses above an energy of about $50 \mathrm{KeV}$. Energy equivalent window settings of the $K, U$, and Th SCAs are shown in Figure 4 next to the SCAs. The digital pulses produced by each SCA are passed to the digital data recording system. In addition, the pulses produced by the SCAs are passed to ratemeters and the count rates are recorded on an analog strip chart.

DIGITAL RECORDING SUBSYSTEM

The digital recording system consists of the components shown in Figure 5 . Pulses from the four SCAs in the linear pulse processing system are counted by four scalers gated on and off in parallel. The scalers, a timer, and a fifth scaler for logging speed are daisy chained together with the controller, and the controller is connected to a digital odometer. The odometer supplies a trigger signal at depth intervals selected by the operator and simultaneously registers depth data. When the trigger signal is received, the controller reads the depth and resets and starts the scalers and the timer. After completion of a time interval selected by the operator, the timer stops the scalers and all the data are transferred to the controller which causes the data to be recorded on a magnetic tape cartridge and on a KSR printer.

\section{SYSTEM PERFORMANCE CHARACTERISTICS}

\section{COUNT RATES}

The standard probe, characterized in Table 1, and used in the spectrometer system has two $\mathrm{Nal}(\mathrm{T} \ell)$ crystals of different. size and volume. Each detector is switch selectable by the operator; the small detector is used when the total count rate in the large detector exceeds about 20,000 cps. Typical count rates 


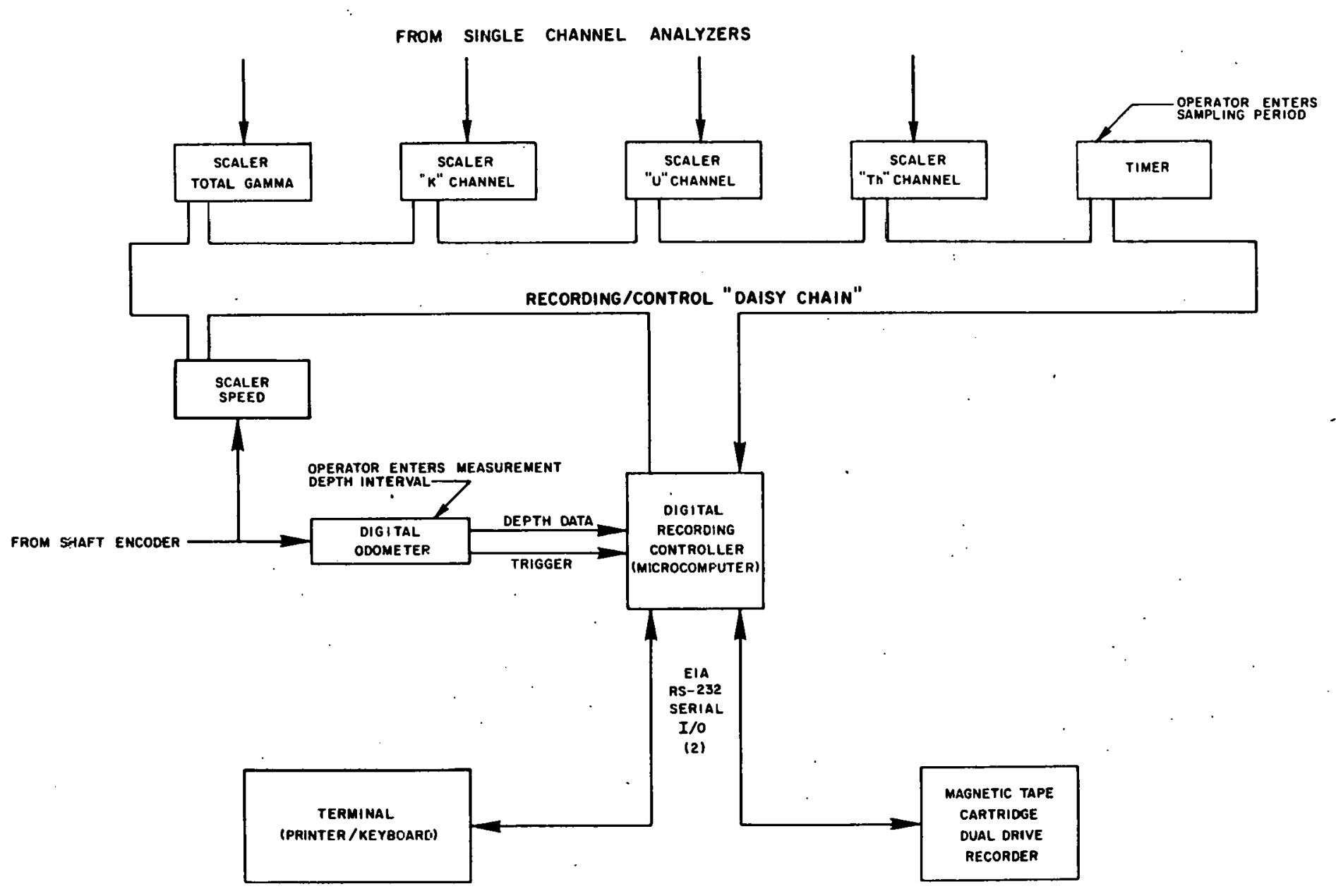

Figure 5

Block Diagram of Digital Data Recording Subsystem 
expected from these detectors in the KUT spectral windows, sketched in Figure 6 , are shown in Table 2.

Table 1

DETECTOR SIZES

\begin{tabular}{|c|c|c|}
\hline & Dimensions & Volume \\
\hline Large Detector & $2^{\prime \prime}$ Diameter $\times 10^{\prime \prime}$ Length & 31 in. $^{3}$ \\
\hline Small Detector & $1-3 / 4^{\prime \prime}$ Diameter $\times 3^{\prime \prime}$ Length & 7.2 in. $^{3}$ \\
\hline
\end{tabular}

Table 2

TYPICAL COUNT RATES VS. ELEMENT CONCENTRATION

(Values shown are stripped" count rates)

\begin{tabular}{|c|c|c|c|}
\hline & $\begin{array}{c}\text { K Window } \\
\text { cps./\% }\end{array}$ & $\begin{array}{c}\text { U Window } \\
\text { cps/ppm eU }\end{array}$ & $\begin{array}{c}\text { Th Window } \\
\text { cps/ppm eTh }\end{array}$ \\
\hline Large Detector & 8.2 & 0.98 & 0.22 \\
Small Detector & 1.8 & 0.19 & 0.043 \\
\hline
\end{tabular}

PULSE PROCESSING SYSTEM PERFORMANCE

Tests of the system using a variety of sources in the energy range between $239 \mathrm{KeV}$ and $2.614 \mathrm{Mev}$ show the linearity to be better than \pm 0.5 percent. Laboratory tests using a pulse generator show that this linearity is maintained over the dynamic range from $30 \mathrm{KeV}$ to $5 \mathrm{Mev}$. Spectral stabllity, which is predominately dependent on the AGC amplifier, is better than $\pm 4.5 \mathrm{KeV}$, at $835 \mathrm{KeV}$, over an ambient temperature range of $33^{\circ} \mathrm{F}$ to $120^{\circ} \mathrm{F}$. Resolution obtained with a ${ }^{54} \mathrm{Mn}$ source placed at each of the two crystals is shown in Table 3 . The reso-

\footnotetext{
"The stripping procedure is found in the section on Calibration Using Logging Múdels.
} 


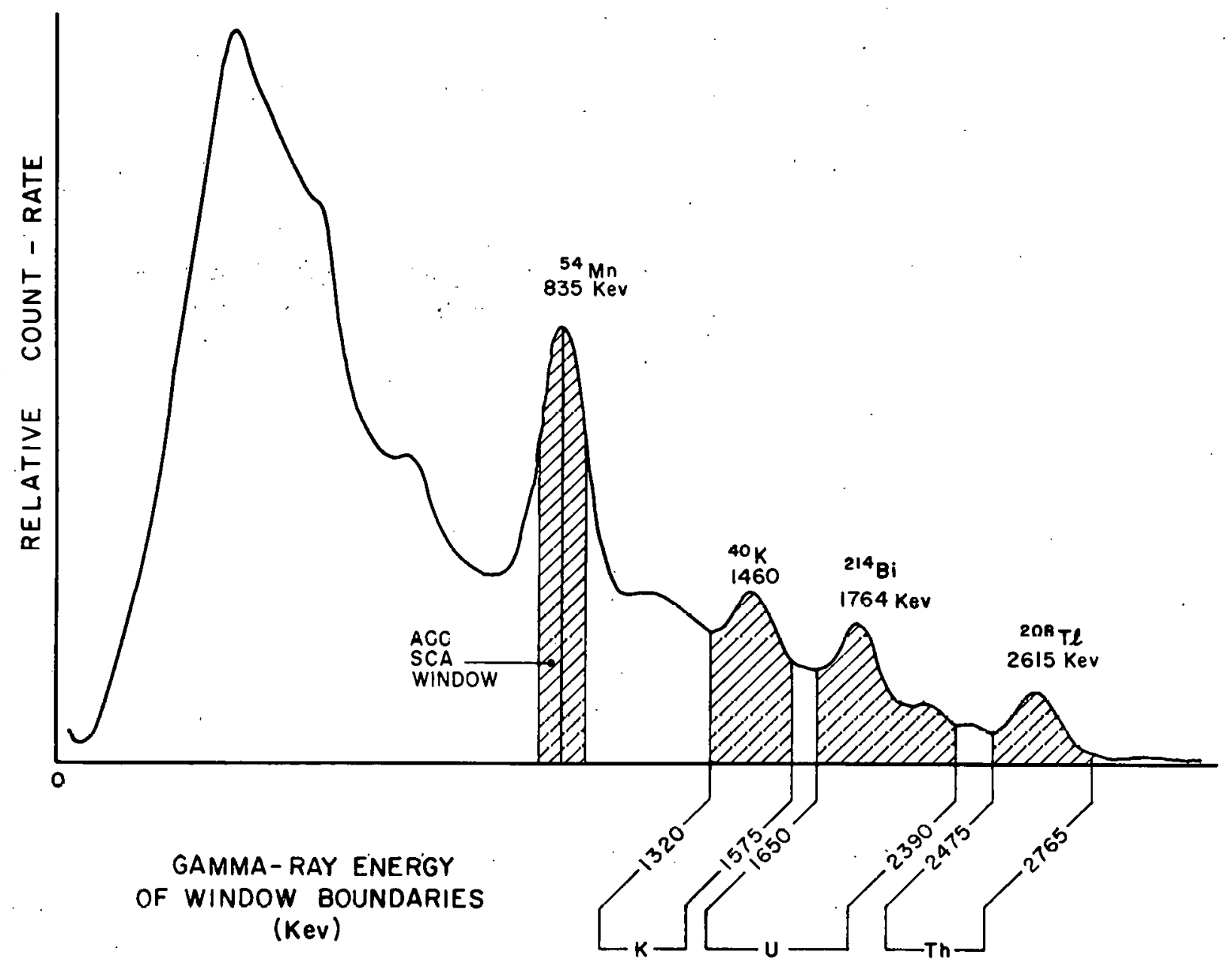

Figure $6^{\prime \prime}$

Diagram of Spectral Window Positions for KUT System 
lution averages about 7.5 percent.

Table 3

TYPICAL SYSTEM RESOLUTION FOR EACH DETECTOR

$\begin{array}{ll}\text { Large Detector } & 7.5-8.5 \% \\ \text { Small Detector } & 7-8 \%\end{array}$

STATISTICS AND LOGGING SPEED

Logging speed can vary considerably depending on the required statistical accuracy and on the radiation intensity present; however, 5 . feet per minute is typical. Generally, counts are accumulated for 10 seconds during each measurement, and measurements are initiated at intervals of 1 foot. The large detector is used to define stratigraphy and low-grade mineralized zones; the small detector is used when the total count rate in the large detector exceeds about $20,000 \mathrm{cps}$.

Table 4 gives examples of measurement statistics for the two detectors. The first line in the table shows an assumed set of concentrations; the other lines in the table are calculated using typical calibration constants for each of the detectors. The count rate statistics in the third line are based on a cuninting intervol of 10 seconds; the statistics shown in the last line result when the count rate data are stripped to yield element concentrations. These statistics are improved when the data are smoothed or when the average of an entire zone is considered.

DATA RECORDING AND DISPLAY

The data are recorded in ASCII code on cartridge magnetic tape. The data recorded for each meası!urement are: 1.) depṭh (seven characters), 2.) counts in each of the four channels (seven characters each), 3.) time interval per 
measurement (seven characters), and 4.) logging speed (seven characters).

Header records such as the borehole ID, location, etc., and the system.configuration records such as instrument settings, gains, etc., also are entered on tape. In addition, the same data recorded on tape are displayed in printed form (i.e., depth, time, total count rate, K-channel counts, U-channel counts, Th-channel counts and logging speed). Figure 7 graphically shows the data format on magnetic tape and Figure 8 is a listing produced by the KSR printer.

Table 4

EXAMPLE MEASUREMENT STATISTICS

\begin{tabular}{cccccccc}
\hline & \multicolumn{2}{c}{ Large } & Detector & \multicolumn{3}{c}{ Smal1 Detector } \\
\hline & $\mathrm{K}$ & $\mathrm{U}$ & $\mathrm{Th}$ & $\mathrm{K}$ & $\mathrm{U}$ & $\mathrm{Th}$ \\
\hline Assumed Element Concentrations & $2 \%$ & $8 \mathrm{ppm}$ & $20 \mathrm{ppm}$ & $4 \%$ & $400 \mathrm{ppm}$ & $800 \mathrm{ppm}$ \\
$\quad \begin{array}{c}\text { Counts per } 10 \text { sec., not } \\
\text { stripped }\end{array}$ & 259 & 208 & 46 & 1337 & 1899 & 359 \\
$\begin{array}{c}\text { Count rate resolution*, not } \\
\text { stripped }\end{array}$ & $6.2 \%$ & $6.9 \%$ & $14.7 \%$ & $2.7 \%$ & $2.3 \%$ & $5.3 \%$ \\
$\begin{array}{c}\text { Computed concentration re- } \\
\text { solution after stripping }\end{array}$ & $20 \%$ & $32 \%$ & $18 \%$ & $140 \%$ & $10 \%$ & $6 \%$ \\
\hline
\end{tabular}

Kesolution = One standard deviation as percent of mean. 


\section{ONE TRACK OF FOUR}

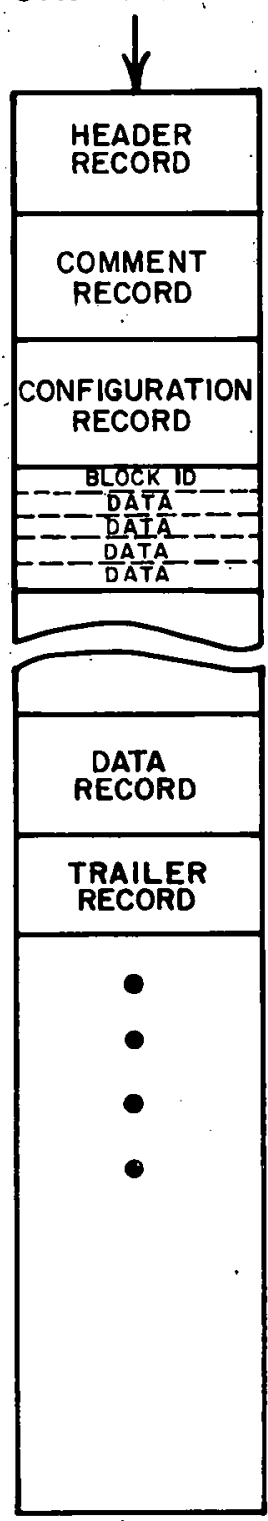

HOLE NO., LOCATION, DATE, OPERATOR, ETC. (56 CHARACTERS)

OPERATOR COMMENTS (65 CHARACTERS)

INSTRUMENT SETTINGS, ETC. (45 CHARACTERS)

DATA RECORD $\left\{\begin{array}{l}\text { BLOCK ID: } 6 \text { CHARACTERS } \\ \text { DATA: } 49 \text { CHARACTERS EACH BLOCK, UP }\end{array}\right.$

TO 4 DATA BLOCKS PER DATA RECORD

HOLE NO., LOCATION, DATE, OPERATOR, ETC. (56 CHARACTERS)

Figure 7

ASCII Formated Data Layout on Magnetic Tape 


\begin{tabular}{|c|c|c|c|c|c|c|}
\hline DEPTH & TIMER & K & U & Th & GAMMA & SPEED \\
\hline 020180 & 001000 & 000300 & 000111 & 000017 & 056839 & 000092 \\
\hline 020160 & 001000 & 000256 & 000144 & 000020 & 066586 & 000092 \\
\hline 020140 & 001000 & 000278 & 000144 & 000029 & 066430 & 000092 \\
\hline 020700 & 00.1000 & 000279 & 000149 & 000034 & 066636 & 000091 \\
\hline 020080 & 001000 & 000327 & 000166 & 000040 & 066675 & 000089 \\
\hline 020060 & 001000 & 000262 & 000.152 & 000026 & 067173 & 000088 \\
\hline 020040 & 001000 & 000315 & 000182 & 000032 & 067375 & 000091 \\
\hline 020020 & 001000 & 000333 & 000174 & 000031 & 067203 & 000091 \\
\hline 020000 & 001000 & 000334 & 000187 & 000054 & 067708 & 000093 \\
\hline 019980 & 001000 & 000363 & 000233 & 000032 & $068 / 79$ & 000092 \\
\hline 019960 & 001000 & 000430 & 000323 & 000071 & 070127 & 000092 \\
\hline 019940 & 001000 & 000495 & 000405 & 000087 & 070758 & 000092 \\
\hline 019920 & 001000 & 000503 & 000530 & 000096 & 071850 & 000091 \\
\hline 019900 & 001000 & 000539 & 000581 & 000097 & 073555 & 000089 \\
\hline 019880 & 001000 & 000600 & 000649 & 000112 & 073863 & 000085 \\
\hline 019860 & 001000 & 000654 & 000643 & 000109 & 074950 & 000090 \\
\hline 019840 & 001000 & 000663 & 000686 & 000125 & 075138 & 000089 \\
\hline 019820 & 001000 & 000716 & 000713 & 000138 & 075298 & 000089 \\
\hline 019800 & 001000 & 000588 & 000706 & 000108 & 075039 & 000090 \\
\hline 019780 & 001000 & 000662 & 000627 & 000110 & 074882 & 000081 \\
\hline 019760 & 001000 & 000596 & 000653 & 000104 & 074183 & 000091 \\
\hline 019.740 & 001000 & 000594 & 000679 & 000120 & 073694 & 000092 \\
\hline 019720 & 001000 & 000643 & 000612 & 000114 & 074169 & 000092 \\
\hline 019700 & 001000 & 000615 & 000639 & 000102 & 074157 & 000090 \\
\hline 019680 & מסחודחח & 000591 & 000563 & 000096 & 073490 & 000086 \\
\hline 019660 & 001000 & 000531 & 000508 & 000095 & 072397 & 000085 \\
\hline 019640 & 001000 & 000454 & 000471 & 000085 & 071374 & 000092 \\
\hline $0196 \overline{20}$ & 001000 & 000438 & 000368 & 000067 & 070726 & 000091 \\
\hline 019600 & 001000 & 000394 & 000366 & 000063 & 069803 & 000091 \\
\hline 019580 & 001000 & 000406 & 000292 & 000067 & 069453 & 000091 \\
\hline 019560 & 001000 & 000401 & 000306 & 000054 & 069936 & 000091 \\
\hline 019540 & 001000 & 000389 & 000317 & 000058 & 069470 & 000092 \\
\hline 019520 & 001000 & 000383 & 000285 & 000048 & 069241 & 000090 \\
\hline 019500 & 001000 & 000325 & 000296 & 000033 & 068923 & 000093 \\
\hline 019480 & 001000 & 000320 & 000206 & 000042 & 068000 & 000091 \\
\hline 019460 & 001000 & 000308 & 000215 & 000040 & 068005 & 000089 \\
\hline 019440 & 001000 & 000322 & 000226 & 000029 & 068258 & 000091 \\
\hline 019420 & 001000 & 000317 & $0 n 0237$ & 000041 & 068011 & 000091 \\
\hline 019400 & 001000 & 000368 & 000259 & 000052 & 068128 & 000083 \\
\hline 019380 & 001000 & 000339 & 000207 & 000053 & 068162 & 000090 \\
\hline 019360 & 001000 & 000260 & 000163 & 000031 & 067225 & 000091 \\
\hline
\end{tabular}

Figure 8

Data Listing Produced by KSR 


\section{LINEAR PULSE PROCESSING SUBSYSTEM - PROBE SECTION}

DETECTORS AND PHOTOMULTIPLIERS

The KUT probe, shown in the assembly drawing in Figure 9, employs two detectors ( 2 inch diameter $\times 10$ inch length and 1-3/4 inch diameter $\times 3$ inch length). The detectors are $\mathrm{Nal}$ ( $T \ell$ ) crystals mounted in high temperature, stainless steel, ruggedized assemblies. The large crystal is manufactured from a multi-crystalline structure to reduce sensitivity to thermal and mechanical shock. Each crystal is coupled to a photomultipiier tube powered from its own high voltage $D C$ to $D C$ converter. Selection of either detector for operation is accomplished through a switch on the surface control panel that actuates a DC relay (Teledyne 1712-22, Figure 10) via an AC coupled control signal transmitted down signal line.

A low strength radioisotopic source $\left(0.2 \mu \mathrm{C} i\right.$ of $\left.{ }^{54} \mathrm{Mn}\right)$ attached to the side of each crystal at the midpoint, provides an energy reference with which the system gain is stabilized. Crystals produce significantly different light outputs depending on where in the crystal a scintillation occurs. Therefore, attaching the point source near the midpoint of the crystal gives the best average linearity relative to an incident (distributed) gamma-ray spectrum. The stabilization. sources are packaged between two thin mylar discs; thus, this configuration can readily be taped to the cylinder wall of the crystal.

PREAMPLIF!ER AND CABLE DRIVER

As shown on the schematic in Figure 10, charge pulses from the photomultiplier anode are converted to voltage pulses in the charge sensitive preamplifier designed around an ultra fast operational amplifier (LHOO32). 


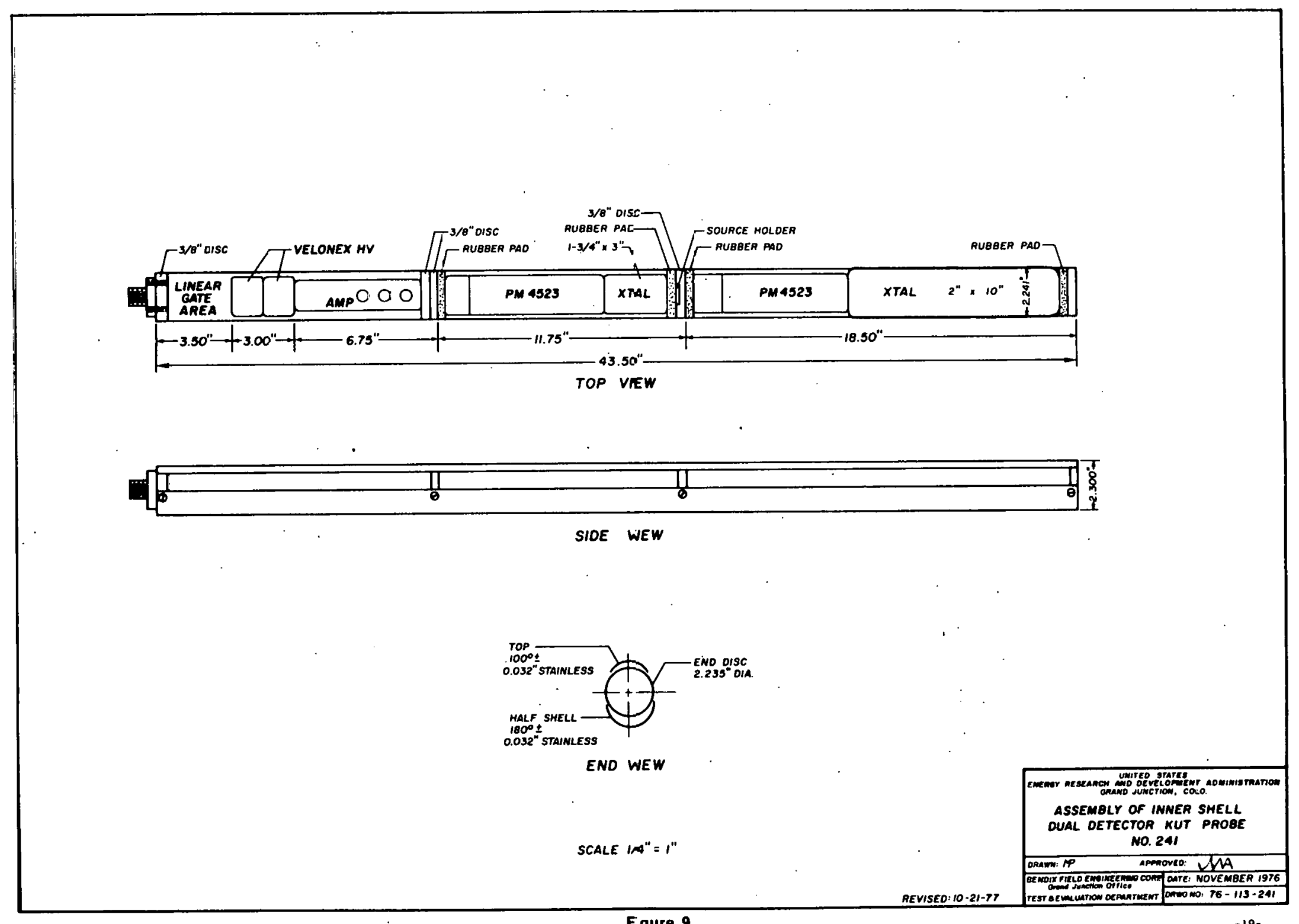

F gure 9

REVISED:10-21-77 


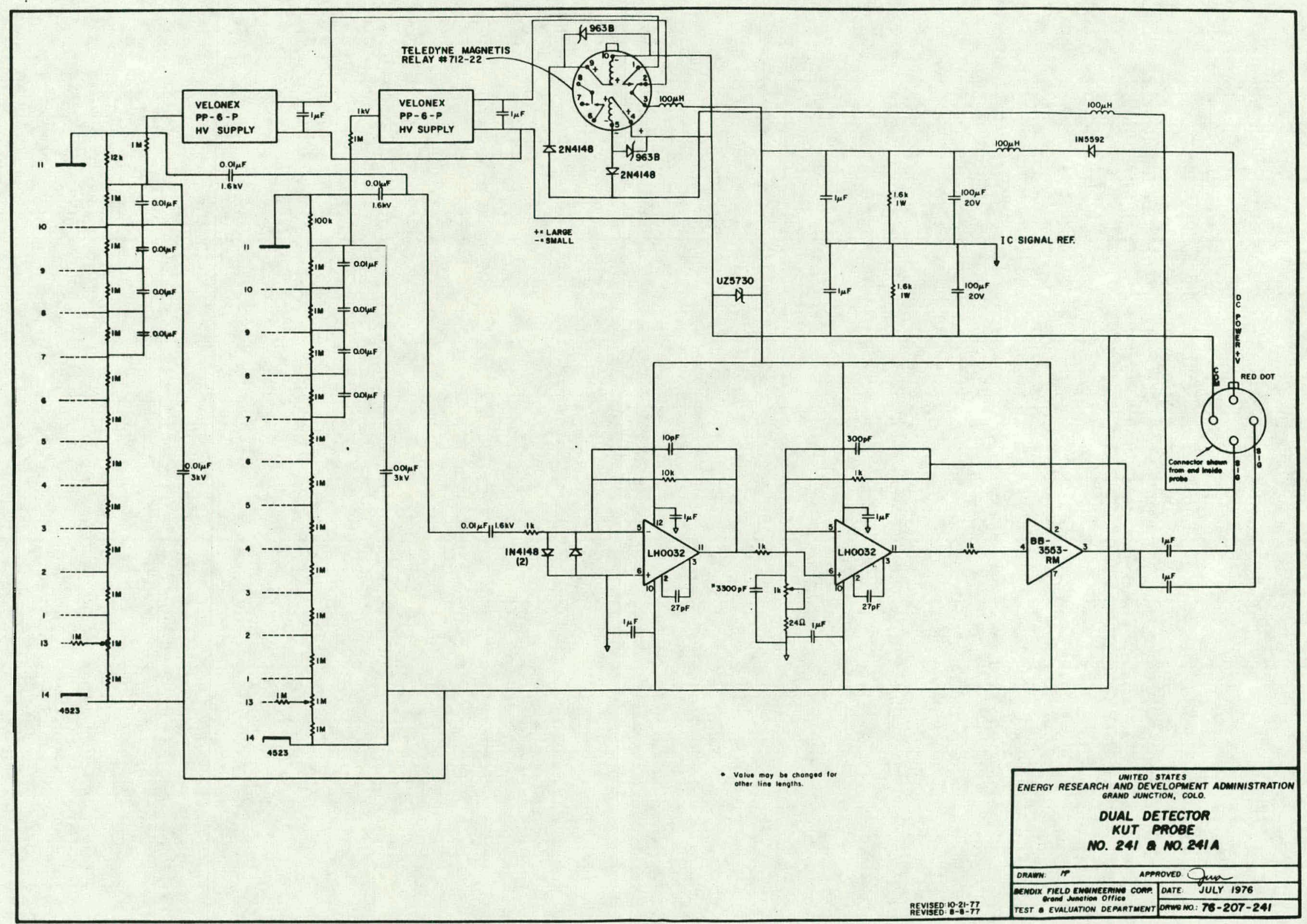


Emphasis of the high frequency components of the pulse is performed in the probe to obtain acceptable pulse widths at the surface, when transmitting over several thousand feet of cable. An ultrafast amplifier (LHO032) is also employed in the high frequency emphasis network. This network emphasizes frequencies beginning at about $50 \mathrm{kHz}$ and flattening at about $500 \mathrm{kHz}$. The cable is driven by an: amplifier (BB-3553-RM) which provides up to $1 / 2$ amp peak current delivering up to 10 volt pulses to two wires of the cable. The circuit used to drive and terminate the 4 wire cable is shown in Figure 11. At the probe, two wires are driven in parallel by the signal amplifier; at the surface one of these wires is left open and the other supplies the signal. Experiments have shown that this method produces shorter pulses by about a factor of two over conventional "single" wire transmission. Figure 12 illustrates pulse shapes occurring at several places in the linear pulse processing subsystem.

\section{LINEAR PULSE PROCESSING SUBSYSTEM - SURFACE SECTION}

Functions performed at the surface by the electronics include:

1.) transmission line matching, 2.) filtering, 3.) pulse shaping, 4.) amplification, 5.) gain stabilization, and 6.) pulse height analysis. Most of these functions are performed by commercially available instruments. The lower half of Figure 4 is a block diagram of the surface section.

\section{LINE MATCHING AND COMPENSATION}

The line is matched by a $70 \mathrm{ohm}$ terminating resistor which reduces pulse distortion and line reflections. The signal is passed through a pole-zero compensation network which reduces pulse undershoot and overshoot and shortens the pules duratinn.

\section{LINEAR PULSE AMPLIFIFR}

The linear pulse amplifier provides filtering, shaping, and amplification. Normal filtering is done by integration with a few tenths of a 


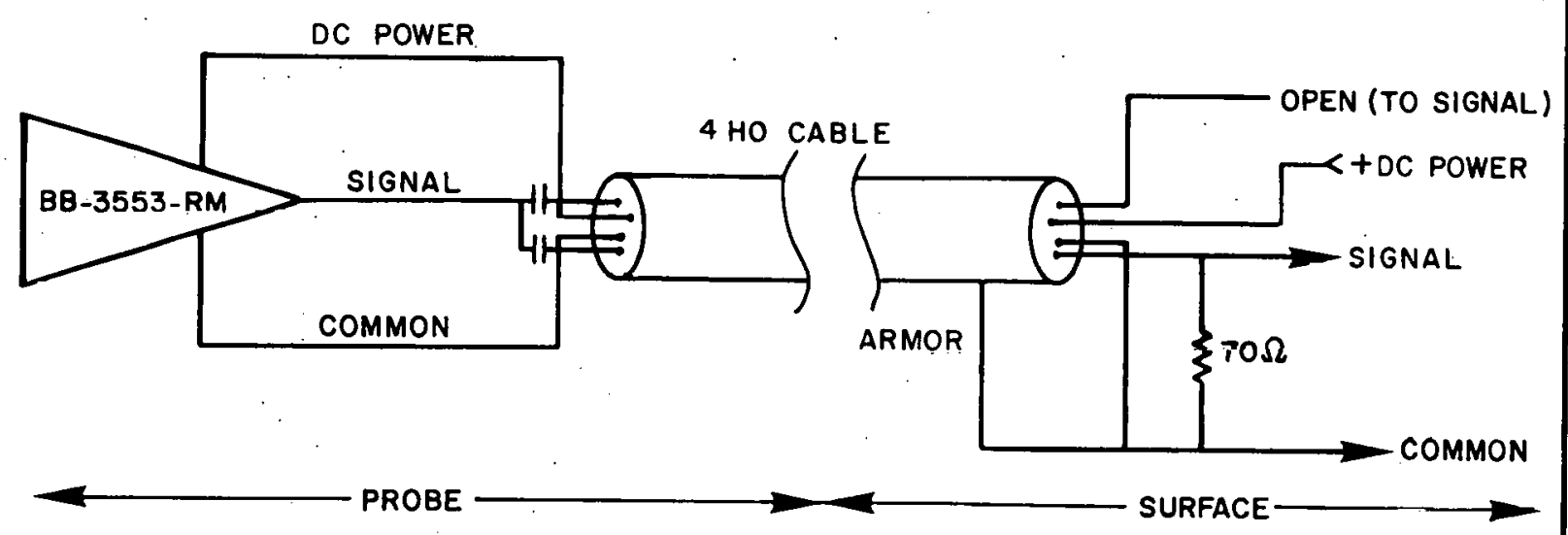

Figure 11

Cable Connections for Pulse and Power Transmission 


\section{LOCATION \\ (See Figure 4)}

Probe: Charge Sensitive Preamplifier Output

Probe: Line Driver Amplifier Output

Surface: Line Matching Terminator

Surface: Pole-Zero Pulse Shaping Network Output

Surface: Linear Pulse Amplifier Output

\section{PULSE SHAPE}

NOMINAL AMPLITUDE

( $\mathrm{Volts}$ )

(For $835 \mathrm{KeV}$ gamma ray)
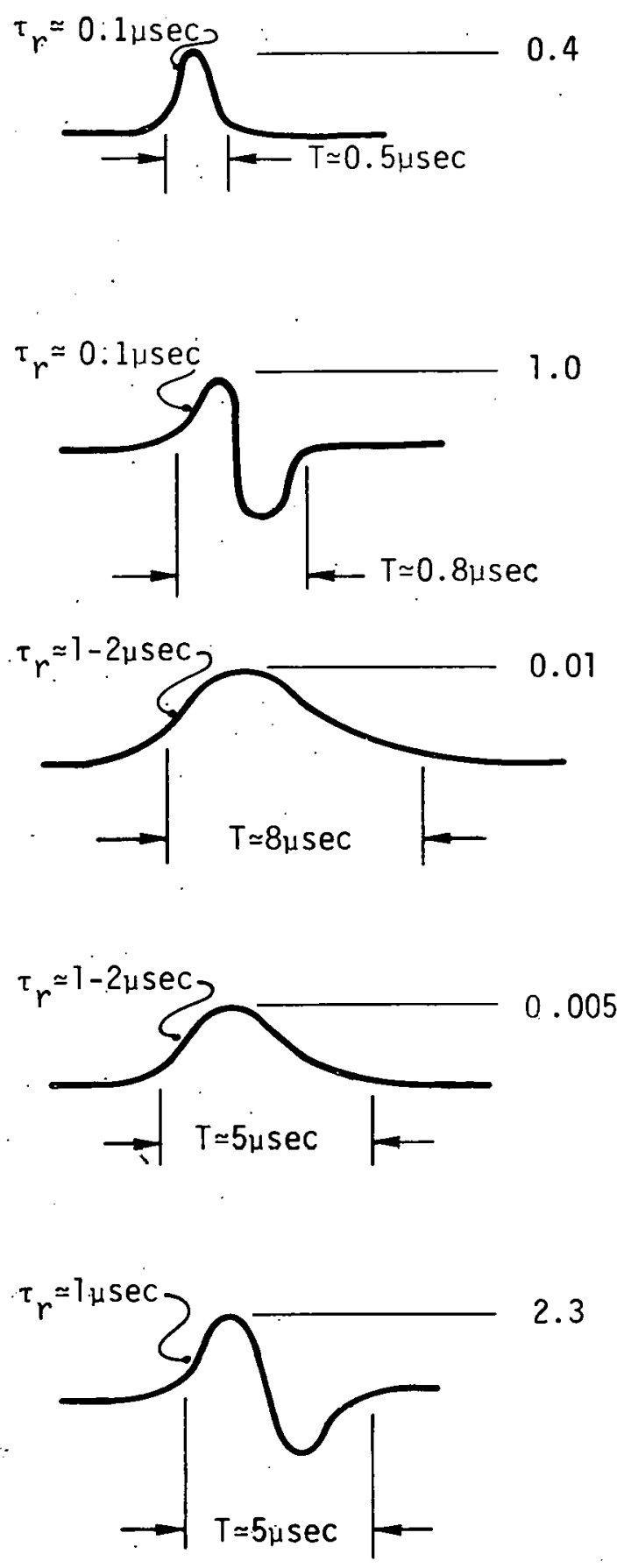

2.3

Figure 12

Typical Pulse Shapes in the Linear Pulse Processing System 
microsecond time constant and normal shaping is carried out by a single 1-microsecond delay line. Integration improves the signal-to-noise ratio and delay line shaping produces a bipolar pulse which reduces both baseline shift and errors in pulse height analysis, particularly at high pulse rates. AUTOMATIC GAIN CONTROL AMPLIFIER (AGCA)

The next basic function performed is spectrum stabilization, which is a method used to hold the ratio between gamma-ray energy and voltage amplitude constant. The automatic gain control amplifier (AGCA) used for this function consists of an electronically variable gain amplifier, a pair of contiguous SCAs and a digital feedback circuit, as shown in Figure 13. The AGCA locks on to the specific spectral peak from the reference source and maintains centering of the peak between the SCAs. The gain variation is accomplished by applying feedback to the variable gain amplifier. Adjustment of the SCA discriminator voltage levels changes the AGCA reference gain so that spectrum energies correspond to desired voltages at the output of the AGCA. In routine operation, settings remain constant and the linear amplifier gain, ahead of the AGCA, is initially adjusted to allow the AGCA to lock on the reference peak. SINGLE CHANNEL ANALYZERS (SCA)

The output of the AGCA is fed into four single channel analyzers. Three of the SCAs are set to respond to $K, U$, and Th by measuring the three corresponding regions of the spectrum $\left({ }^{40} \mathrm{~K},{ }^{214} \mathrm{Bi},{ }^{208} \mathrm{Tl}\right)$; the fourth SCA responds to total count by measuring all pulses greater than $50 \mathrm{KeV}$. The SCAs are operated in the AC coupled input mode and each SCA has its upper and lower discriminators precisely adjusted to the voltage level representing the upper and lower bounds of its corresponding energy region. Pulse heights falling within the energy window generate a logic pulse output; all other pulses are ignored. Discrimination level (window) stability is critical. It must remain stable to better than 0.005 percent $/{ }^{\circ} \mathrm{C}$ over the operating temperature 


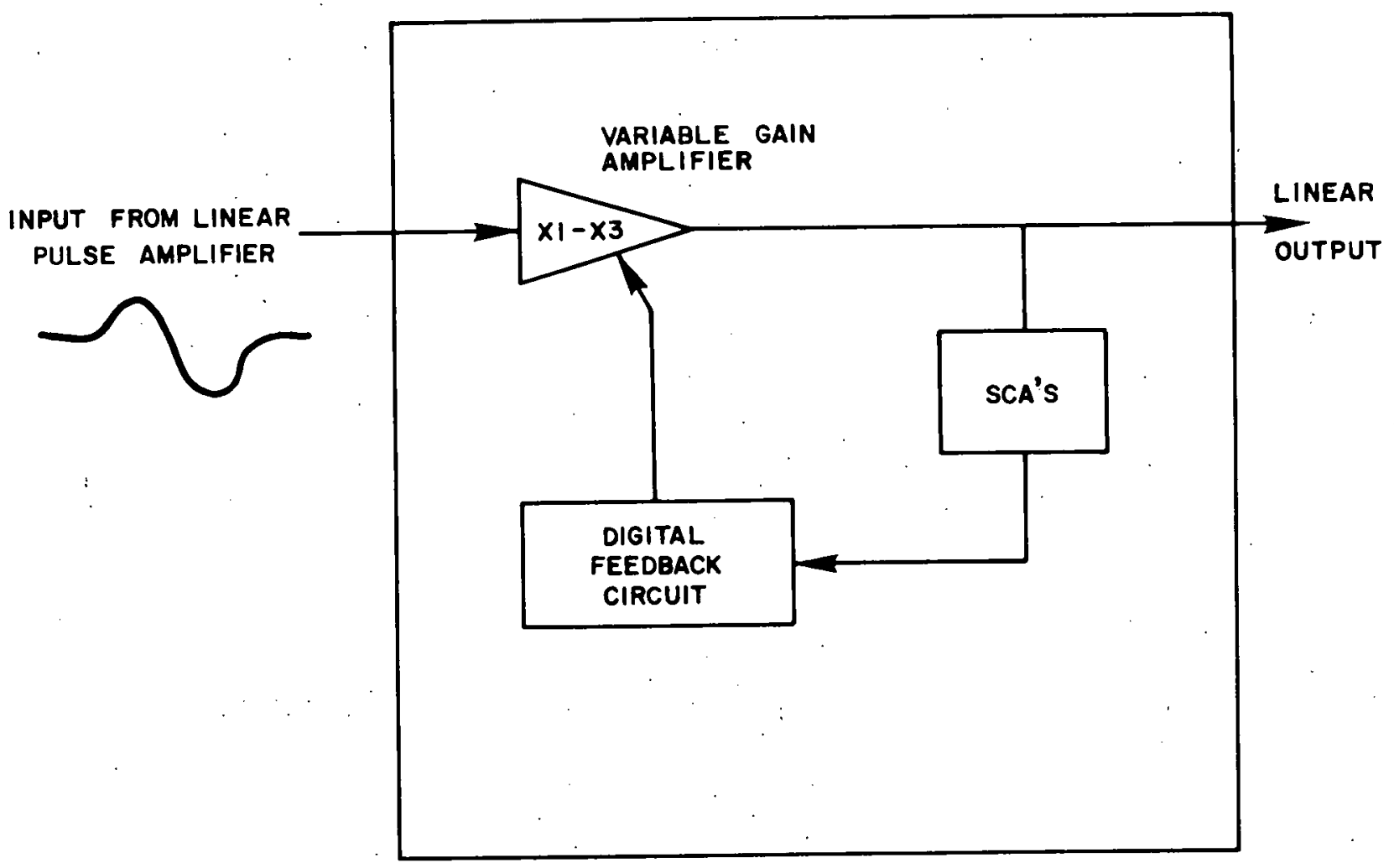

Figure 13

Simplified Block Diagram of Automatic Gain Control Amplifier 
range of the system, if unacceptable errors in the resulting data are to be prevented.

\section{RATEMETER}

The ratemeter is a commercial unit which averages the output pulse rate from the total count SCA. The ratemeter provides a smoothing time constant to reduce random fluctuations caused by the statistics of the pulse train, and produces an analog signal which drives a strip chart recorder.

\section{DIGITAL DATA RECORDING SUBSYSTEM}

Figure 5 is a block diagram of the Digital Data Recording Subsystem. SCALERS AND TIMER

The scalers and timer are commercial units which can be used in either a scaling or a timing mode. The inputs to the scalers are digital pulses from the SCAs. The scalers count these pulses for a selected period of time controlled by the timer. The timer provides a gating signal to five scalers (the fifth scaler is for logging speed), and, at completion of the selected time period, the data are read from the scalers and timer by the controller. The scalers and timer are connected in a daisy-chain loop.with the controller; the controller issues control signals causing the data to be transmitted back to it, character by character.

DIGITAL ODOMETER

The digital odometer is similar to commercially used.units. It is driven from an optical encoder coupled to a cable measuring wheel. The odometer generates trigger pulses, which initiate a counting sequence at depth intervals of $0.1,0.2,0.5,1.0,2.0,5.0$, or $10.0 \mathrm{ft}$, as selected by the operator. The contents of the odometer and scalers are read out serially by character into the controller. A six digit LED display provides visual indication of probe depth and a six digit thumbwheel switch provides the capability for manual input and initialization. 


\section{CONTROLLER}

The data controller, diagrammed in Figure 14 and shown disassembled in Figures 15 and 16 , is a microcomputer designed and built in the BFEC-ATD electronics laboratory; it contains an Intel 8080 microprocessor. The processor has 1 kilobyte of random access memory and up to 6 kilobytes of programmable, read-only memory. Input/ouput chips in the microcomputer consist of: 1.) two universal synchronous/asynchronous receiver/transmitter (USART) devices for communication with the keyboard send-receive (KSR) terminal and with the cartridge recorder; 2.) one programmable, peripheral interface chip for communication with the digital odometer and the daisychained counters; and 3.) one parallel input/output chip for driving indicators and alarms. The system is mounted on two standard wire wrap boards and is housed in a standard 3-wide NIM module.

The data controller initiates a data collection period (upon receipt of the trigger from the digital odometer) by resetting and starting the scalers and reading the depth from the odometer. Upon completion of the prescribed time period, the data are read from the scalers. The data are buffered by the microprocessor until all data pertaining to a particular depth have been accumulated. The data are then transferred to the cartridge recorder and optionally printed on the KSR terminal.

Five different types of tape records are written (as shown in Figure 7):

1.) A header record, which contains information pertaining to the specific borehole (time of year, location, etc.). These records are generated by the operator in a standard format, as prompted by the microcomputer.

2.) A comment record, which contains miscellaneous information entered by the operator. 


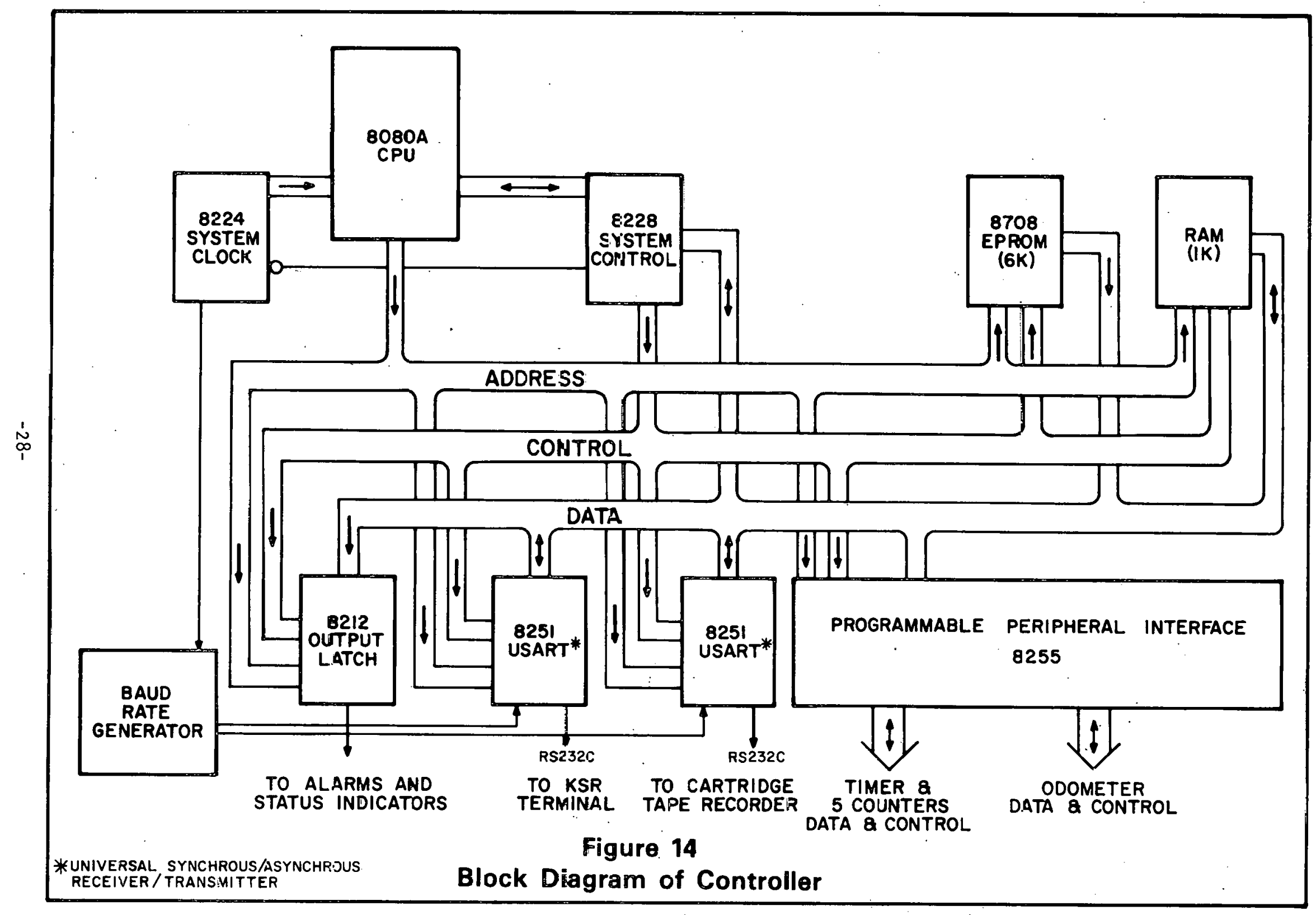




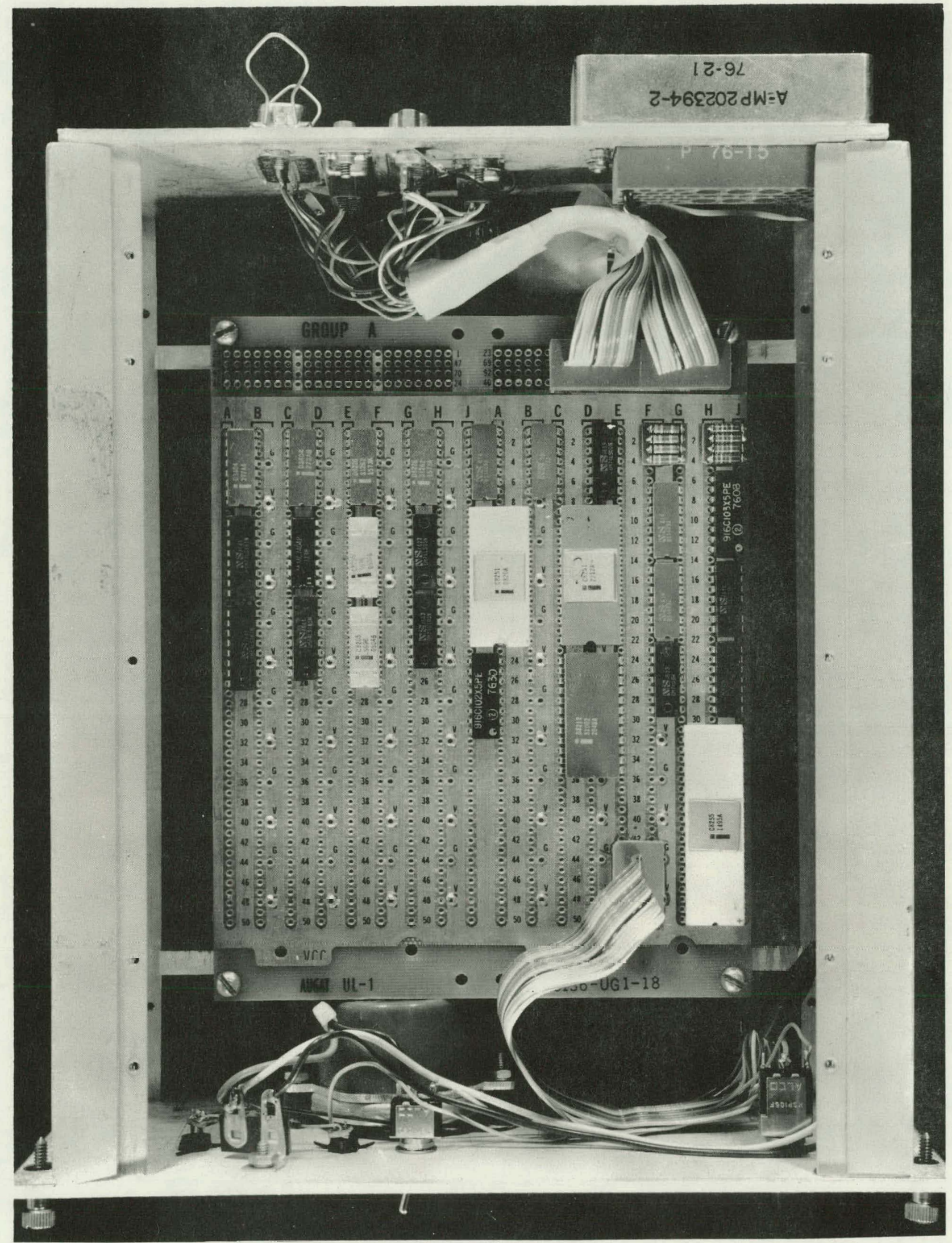

Figure 15

Data Controller Microcomputer-Right side view 


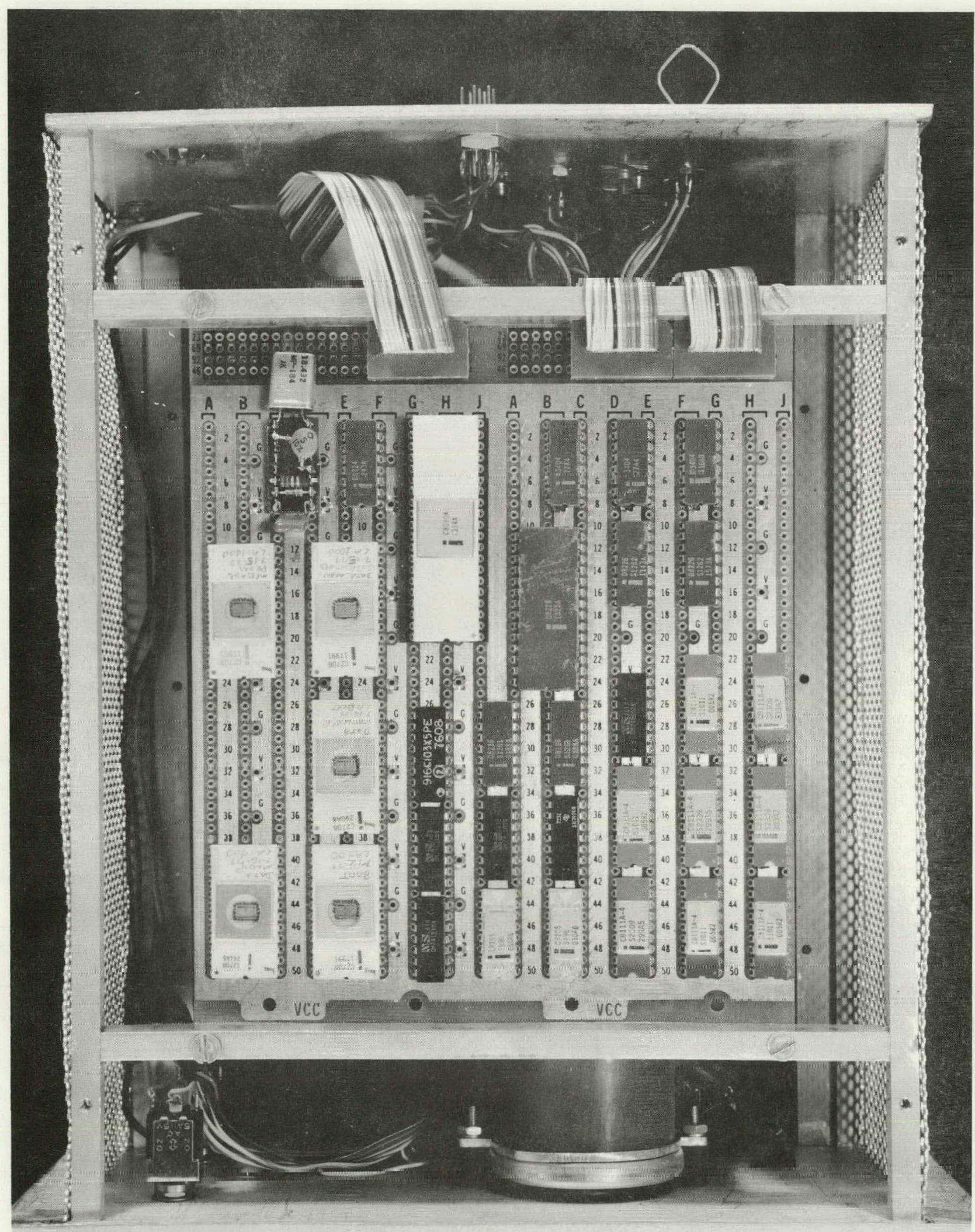

Figure 16

Data Controller Microcomputer-Left side view 
3.) A configuration record, which contains information pertaining to the specific truck instrumentation configuration (switch positions, amplifier gains, etc.). These records are generated by the operator after computer prompting.

4.) Data records, which contain the data read from the odometer and the counters. These data are tagged and written on cartridge magnetic tape, as shown in Figure 7.

5.) A trailer record, which contains the same information as the header record.

KSR TERMINAL

The terminal is a commercially available, thermal-dot," matrix printer with full ASCII keyboard. The printer is used to record both data and operator prompting information. Figure 8 illustrates the data format which contains 1.) depth, 2.) time interval, 3.) counts in each of four channels, and 4.) logging speed. DIGITAL, MAGNETIC TAPE CARTRIDGE RECORDER.

A dual-drive, magnetic tape cartridge recorder is used to collect the data for later processing. Data from the controller are transmitted to this recorder in ASCII code via a standard EIA RS-232 serial interface. The recorder buffers the data for each record before the record is recorded on tape (See Figure 7), and also provides write error indication and other feedback signals required for reliable data recording. The data are recorded on a $3 M$ type cartridge with a capacity of about $300 \mathrm{~K}$ bytes on each of its four tracks. 
SYSTEM CALIBRATION

Calibration of the system involves two steps. The first step is carried out in the laboratory and consists of adjustments to instruments and circuits. The second step is calibration performed in borehole test models to determine relationships between count rates and radioelement concentrations. INSTRUMENT ADJUSTMENTS

Instrument adjustments consist of 1. ) setting photomultiplier gains, 2.) setting linear amplifier gain, 3.) setting AGCA gain and window width, and 4.) setting SCA window thresholds and widths. System performance characteristics, which are checked during this part of the calibration, are linearity and resolution.

PHOTOMULTIPLIER GAIN ADJUSTMENTS

The high voltage power supplies for the photomultipliers are adjusted so that the pulse amplitude from an $835 \mathrm{KeV}$ gamma ray falls at about onesixth the maximum linear range of the probe electronics. Because $2765 \mathrm{KeV}$ is the maximum energy of interest in the spectrum, the upper half of the linear range is available as a safety margin to accommodate gain shifts due to temperature changes and other sources.

\section{AUTOMATIC GAIN CONTROL AMPLIFIER ADJUSTMENTS}

The AGCA is adjusted such that the window width corresponds to $51 \mathrm{KeV}$ and it is adjusted such that a 2.3 volt pulse at its output corresponds to the $54 \mathrm{Mn}$ energy peak when the AGCA gain is in the center of its range.

\section{SINGLE CHANNEL ANALYZER ADJUSTMENTS}

Before setting the SCAs, a multichannel analyzer (MCA) is used to check system linearity and resolution at the output of the AGCA. Remedial action 
is taken if the linearity is not better than \pm 1 percent (from a least-squares

$\mathrm{fit}$ ) in the $835 \mathrm{KeV}$ to $2615 \mathrm{KeV}$ range, or if resolution of the reference eñergy level is not within 8.5 percent for either detector.

Accurate adjustment of the SCA windows is accomplished by coincidence gating of each SCA output with the complete spectrum (at the SCA inputs). During coincidence gating, the MCA displays that part of the spectrum being accepted by a SCA. After calibration of the MCA (in single channel PHA mode), SCA window levels and widths are adjusted (with the MCA in coincidence mode) until the MCA shows that the SCA thresholds correspond to the thresholds shown in Figures 4 and 6.

CALIBRATION IN LOGGING MODELS

MODEL DESCRIPTION

The present facilities for calibrating gamma-ray spectral logging probes consist of four borehole test models. The first three borehole. models, shown in Figure 17, are constructed of concrete mixes with ore zones having enhanced concentrations of potassium, uranium, and thorium. Each of these three models has ore zones 5-feet thick and each model has barren zones 3-feet thick, above and below the ore zone. The $K, U$, and Th concentrations of these three models are listed in Table 5. A recently constructed fourth KUT model is a watel ractur model having a mixture of $K, U$, and Th concentrations and having five different hole sizes. This model is shown in Figure 18 along with the target values of $K, U$, and Th concentrations. These target concentrations may be accurate only to about $25 \%$, because assay data for the model were not available before publication of this report.

The ore zones of the $K, U$, and Th logging models, in conjunction with the lowor barren zone (boekgrouind) of lhe $k$ mudel, are used to determine the sensitivity of the spectral system to the presence of $K, U$, and Th radiation. 


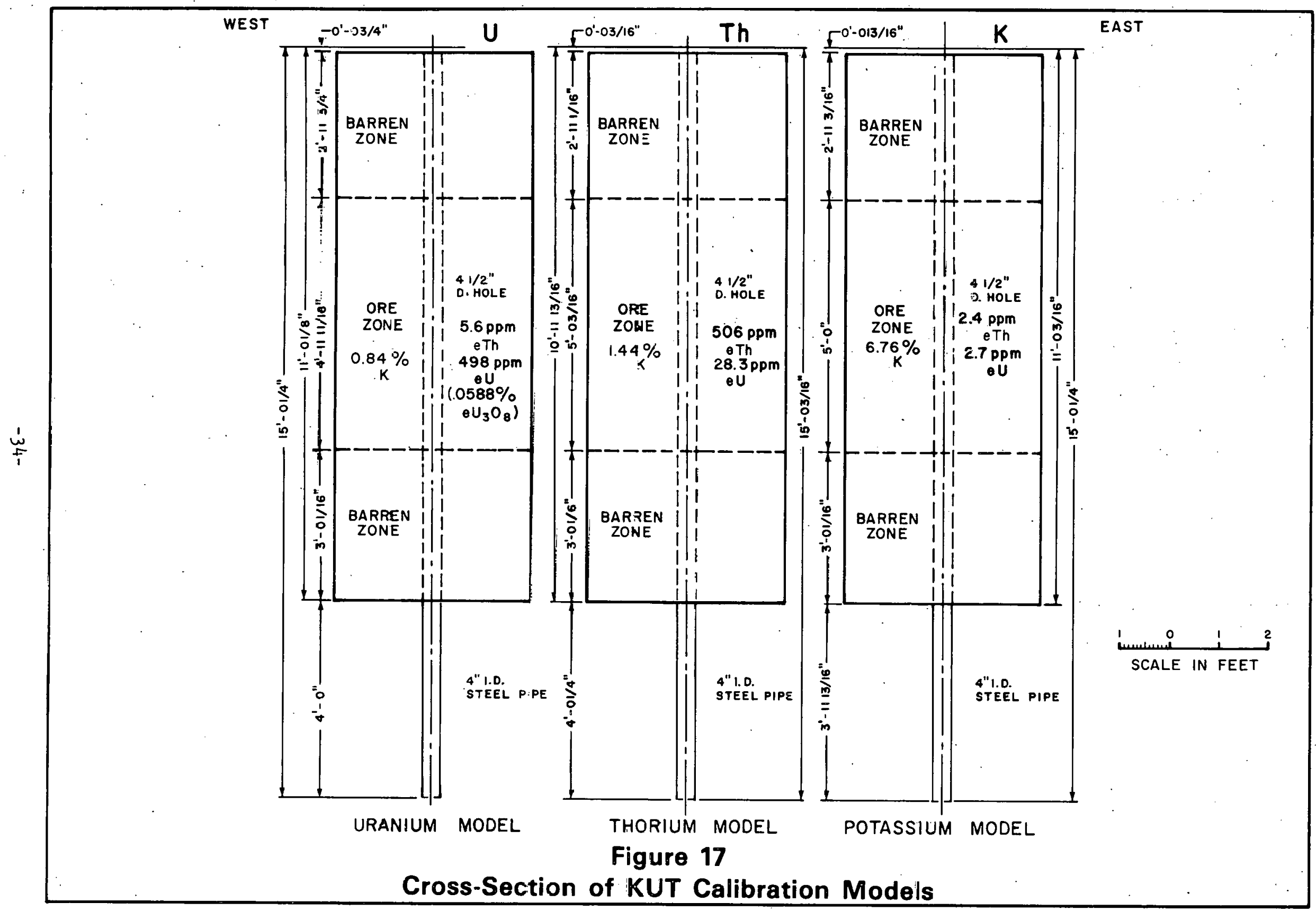




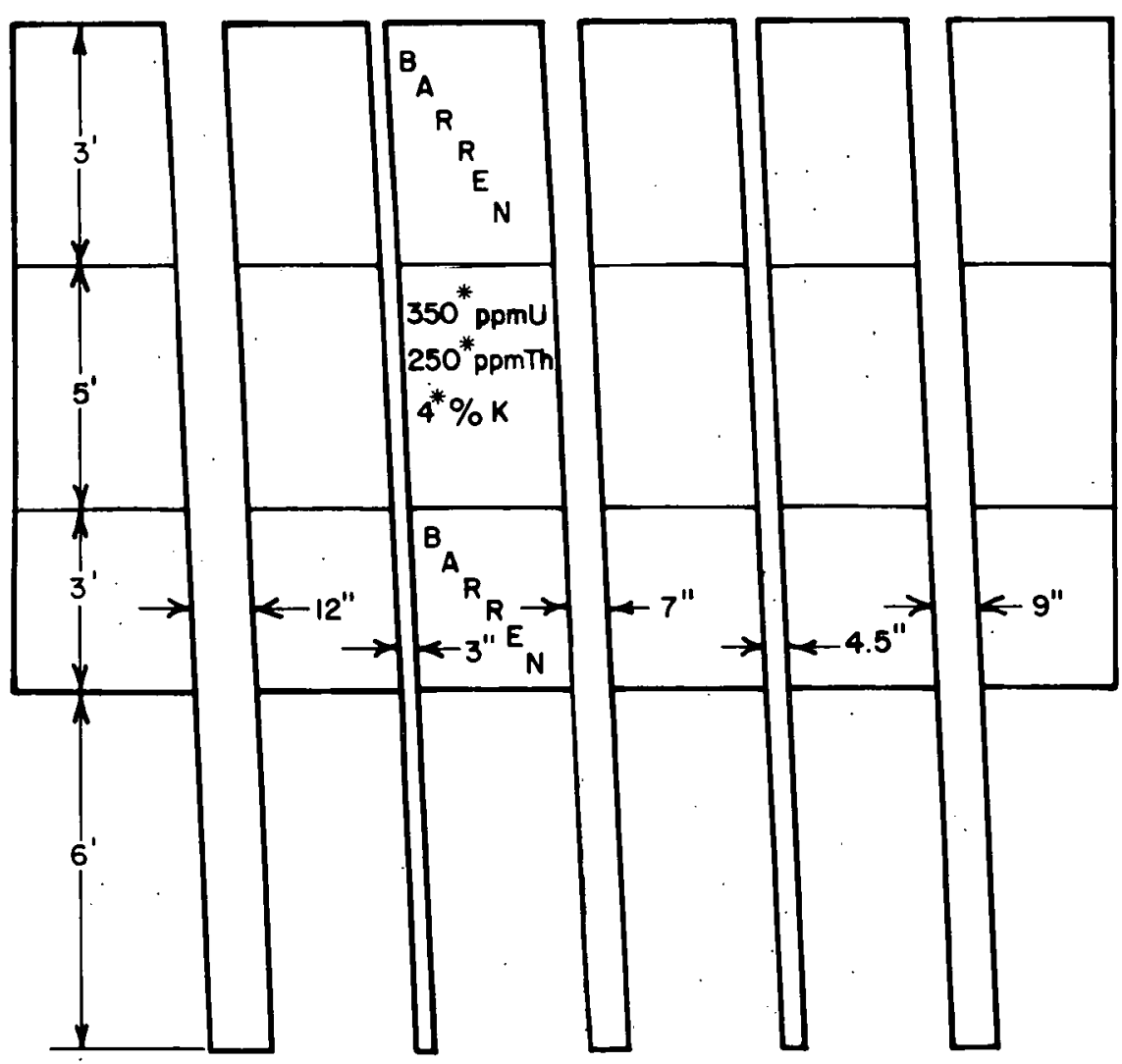

* Target, design concentrations, as builf; assays not available at time of publication.

Figure 18

KUT Water Factor Model 
However, gamma rays from each of the three radivelements contribute counts to each of the spectral windows; therefore, it is necessary to calculate these contributions to each window to establish the stripping ratios.

Table 5

GAMMA-RAY SPECTRAL LOGGING MODEL CONCENTRATIONS

\begin{tabular}{|c|c|c|c|c|}
\hline Logging Model & Zone & \% & ppm eU & ppm eTh \\
\hline K & Upper Barren & $2.00 \pm 0.07$ & $2.6 \pm 0.3$ & $7.4 \pm 0.8$ \\
K & Ore & $6.76 \pm 0.18$ & $2.7 \pm 0.3$ & $2.4 \pm 0.6$ \\
K & Lower Barren & $1.89 \pm 0.05$ & $2.7 \pm 0.3$ & $7.4 \pm 1.3$ \\
U & Upper Barren & $2.01 \pm 0.05$ & $2.6 \pm 0.2$ & $8.0 \pm 0.4$ \\
U & Ore & $0.84 \pm 0.24$ & $498.3 \pm 12.1$ & $5.6 \pm 1.3$ \\
Th & Lower Barren & $2.16 \pm 0.09$ & $3.4 \pm 0.6$ & $8.7 \pm 0.5$ \\
Th & Upper Barren & $1.98 \pm 0.04$ & $2.4 \pm 0.2$ & $8.0 \pm 0.7$ \\
Th & Ore & $1.44 \pm 0.08$ & $28.3 \pm 1.0$ & $505.5 \pm 12.1$ \\
& Lower Barren & No samples available for analyses. & \\
\hline
\end{tabular}

DATA HANDLING PROCEDURES

Differential count rates are used to calculate llie stripping ratios. Static count rates are obtained in the ore zones of the $K, U$, and $T$ models and a background count rate is obtained from the lower barren zone of the $K$ model. Theii, the hackground count rates in each window are subtracted from the count rates obtained in each window in each ore zone. Also, to correct for background, the element concentrations in the lower barren $k$ model are subtracted from the concentrations in the ore zones of each model. 
The relationship between observed differential counts and differential concentrations obtained from the three calibration models is

$$
R_{i j}=\sum_{\ell=1}^{3} A_{i \ell} C^{C}{ }_{l j},
$$

where

$R_{i j}=$ differential counts in the $i$ th window from the $j$ th logging model,

$C_{\ell j}=$ differential cncentrations of the $\underline{\ell t h}$ element in the $j \underline{\text { th }}$ logging model, and $A_{i \ell}=$ a constant relating counts in the $i$ th window to the concentrations of the lth element.

Equation (1) can be written, in matrix notation, as

$$
[R]=[A][C] \text {, }
$$

where $[R],[A]$, and $[C]$ are $3 \times 3$ matrices.

Because [R] and [C] are measured quantities, the matrix [A] can be calculated from

$$
[A] \doteq[R][C]^{-1},
$$

where [C] ${ }^{-1}$ represents the inversion of matrix [C].

If a single "model" is chosen to be an unknown borehole, the subscript "j" in equation (1) is no longer necessary, so [R] and [C], in equation (2), become $3 \times 1$ matrices. Then, equation (2) can be inverted to yield

$$
[C]=[A]^{-1}[R] \text {. }
$$

This set of equations is used to calculate concentrations from the observed count rates; the elements of $[A]^{-1}$ are the stripping ratios.

\section{LOG RESPONSE CORRECTIONS}

Calibration data are acquired in the $K, U$, and Th logging models in a 4-1/2 inch dlameter, air filled (dry) borehole. Generally, field conditions are different from those found in the calibration models, so the field logs must be corrected for these different conditions before the recorded count 
rates (counts per second) are converted to concentrations (percent $\mathrm{K}$, ppm eU, ppm eTh). The count rates are multiplied by the appropriate correction factors before the count rate data are converted to concentrations. Approximate correction factors for one of the spectral probes, acquired experimentally from the KUT water factor model, are shown in Figure 19. This plot shows that the correction factor increases as the borehole diameter increases, and is approximately the same for each spectral window. The data shown are for the large (2 inch $\times 10$ inch) detector.

The use of ancillary probes (neutron-neutron, density, caliper, resistivity, temperature, sonic, etc.), when logging a field borehole, yields other borehole and formation properties, such as moisture content, density, temperature, lithology, and hole diameter. When these field borehole and formation properties are not the same as those of the calibration model, correction factors can be applied to the raw spectral data. 


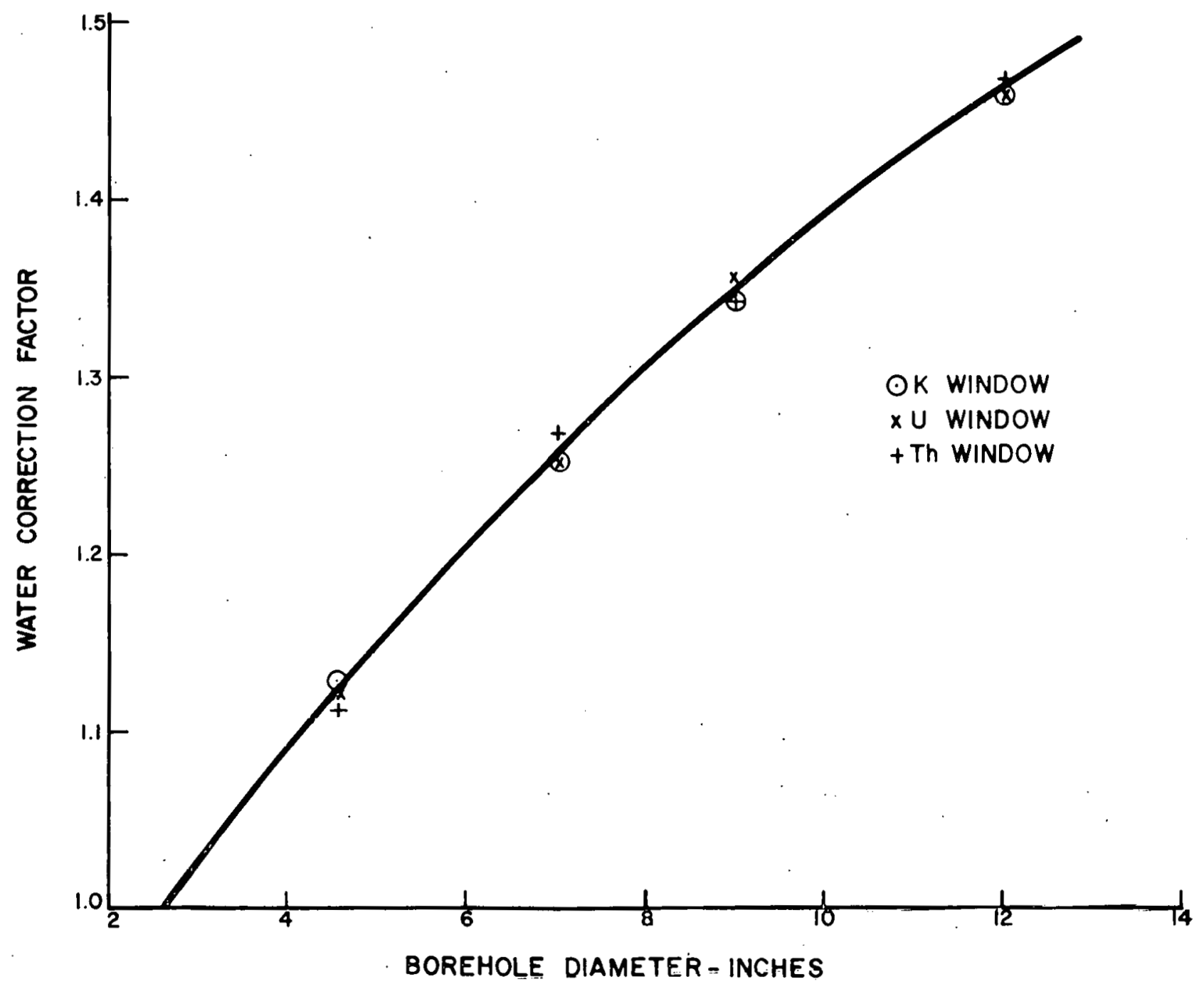

Figure 19

Approximate Borehole Water Correction Factors 
There are two primary uses of borehole gamma-ray spectrometer (KUT) data relative to gross gamma-ray data. One is improved reliability in assessing uranium and thorium ore grade, particularly in disequilibrium situations and in low-grade accumulations. A second is in the increased capability available for interpretations concerning lithology and lithologic relationships. These applications are considered below; examples of KUT logs are also presented.

\section{ORE GRADE ASSESSMENT}

The borehole KUT method of ore grade assessment is more accurate than the gross gamma-ray $\log$ method when the $K$ and Th concentrations significantly contribute to gross-count rate. Because gross gamma-ray log calibrations generally are based upon measurements in models containing only uranium (Duray, 1976), these logs provide a reasonably accurate measure of the uranium concentration.when 1.) most of the count rate in the ore zone originates from uranium-daughter products, or 2.) the proportion of $K$ and Th remain constant with respect to the uranium content. Therefore, in an exploration drilling program, the influence of $k$ and Th on ore grade estimates in one hole and their distribution between holes can be determined. Lngs, which yield potassium content, are essential in determining the amount of clay present in a formation and in detectlny putash deporits (Hurley, 1956).

\section{GENERAL LITHOLOGIC CORREIATION}

Several applicatlons of the KUT $\log$ in defining lithology can be identified. The geochemical concentration and distribution of $K, U$, and Th relationships, in a borehole, can be used in establishing lithologles. When local and regional $k$, $U$, and Th concentrations can be related to lithologies (Wichmann, et al., 1975; Lock and Hoyer, 1971), these data can be used to determine $U$ and Th ore potential in a given area, and to detect proximity to ore accumulations by establishing 
approximate concentrations or ratios of concentrations of $K, U$, and $T h$, from logs. One example of the use of the $K$ content and distribution is in differentiating between rocks dominated by potassium feldspars and those which are essentially composed of sodium-calcium feldspars. An example of this kind of feldspar differentiation is demonstrated in a log example from the Pedro Mountains, which is discussed in a later section. In sedimentary formations, KUT $\log$ data can aid in locating facies changes and alteration zones. Where such determinations are difficult, the discrimination of time-equivalent units. sometimes is possible.

Other interesting applications of gamma-ray spectral measurements have been reported. These include:

1.) Quality control and monitoring in mills and mines, as well as surface and subsurface KUT analyses (Kosanke, et al., 1975; Salamon, 1976; Hurley, 1956).

2.) Stratigraphic mapping between wells where other methods (including petrographic) fail, as in parts of the Phosphoria Formation, and the determination of mica content of shales which permits correlation in Jurassic Reservoirs of the North Sea (Evans, 1967; Marett, et al., 1976) .

3.) Determination of the cause of gamma-ray anomalies behind casing and the detection of facies changes in uncored walls (Wichmann, et al., 1975; Lock and Hoyer, 1971).

4.) Reconnaissance exploration for uranium, using logging measurements in up-hole sections of existing petroleum and water wells (Dodd and Eschliman, 1971). 


\section{RECONSTRUCTION OF LITHOLOGY FROM SPECTROMETER MEASUREMENTS}

\section{ENVIRONMENTAL CONSIDERATIONS}

In addition to yielding all the information available from a conventional gamma-ray $\log$, the spectrometric system provides enhanced capabilities for subsurface interpretations based on the relative and approximate concentrations of potassium, uranium, and thorium. Furthermore, relationships between the Th to U ratio (Th/U ratio) and a.) rock type and mineralogy, b.) degree of oxidation and weathering, and c.) relative position of a rock unit in a depositional basin (!.e., tlie distance from an original shnre) have been demonstrated (Hurley, 1956; Adams and Weaver, 1958; Marett, et al., 1976; Wickmann, et al., 1975).

In general, sedimentary rocks have a greater range in thorium and uranium concentration and in $T h / U$ ratios than are found in primary igneous rocks. The general terrestrial Th/U ratio is about three or four. Available data show that the Th/U ratio in sedimentary rocks varies from less than 0.02 to more than 20 . Uranium values range from less than 0.1 to $250 \mathrm{ppm}$ or greater; thorium values range from less thall 0.1 to over $130 \mathrm{ppm}$. Published data suggest that oxidation during weathering is a primary mechanism for separating thorium and uranium. The separation of thorium and uranium in sedimentary processes results because uranium can be oxidized to the very soluble uranyl form, while thorium has no comparable state in surface or near-surface environments; and because thorium, in general, is much more readily concentrated in placers and other residual deposits than uranium.

ROCK TYPE CIASSIFICATION

Thorium and uranium concentrations vary with the prevalent erosional and depositional conditions. Three arbitrary, general rock types can be categorized on the basis of Th/U values:

1.) When Th/U ratios are less than two to three, extraction from sea or 
fresh water is the major mechanism for the fixation of uranium in sediments. Many marine black shales and phosphate rocks belong to this group and their uranium content is commonly more than $10 \mathrm{ppm}$ and often exceeds $100 \mathrm{ppm}$. Carbonate rocks, low in detrital silicates, also belong to this group; their uranium content rarely exceeds 3 ppm. Finally, many cherts, anhydrites (and other evaporites) and coals are included in this group.

2.) Th/U ratios greater than seven to ten develop by concentration of high Th/U resistates such as Monazites in beach sands and placers, and through removal of uranium by extreme weathering and leaching, which leaves the relatively insoluble thorium behind in higher than normal concentrations. Many placers and Bauxites belong to this group; their thorium contents often exceed $50 \mathrm{ppm}$. Residual clays, continental shales, Bentonites (Kaolinitic), and deeply weathered soils also belong to this group; their thorium content is nominal, $10 \mathrm{ppm}$ or so, but often it exceeds $20 \mathrm{ppm}$.

3.) Intermediate Th/U ratio values (two or three to seven to ten) can result from poor weathering and rapid deposition of igneous rock detritus, or can arise from mixtures of material derived from both low-ratio and high-ratio sources. Many gray and green shales, marine red and yellow shalcs, and yraywackes belong to this group.

\section{IDENTIFYING ROCK TYPES USING GAMMA-RAY SPECTROMETER DATA}

A very incomplete list of $K, U$, and Th concentrations and Th/ $U$ ratios of geologic materials appears in Table 6 . Based on these approximate data, and other observations, the following conclusions are valid:

1.) $U$, Th, and $K$ are present in shales in amounts that are roughly inversely proportinnal to thoir gamma-idy actlvley; in the average 
TABLE 6

SOME AVERAGE BACKGROUND VALUES OF $U$, Th, $K$, AND Th/U IN GEOLOGIC MATERIALS

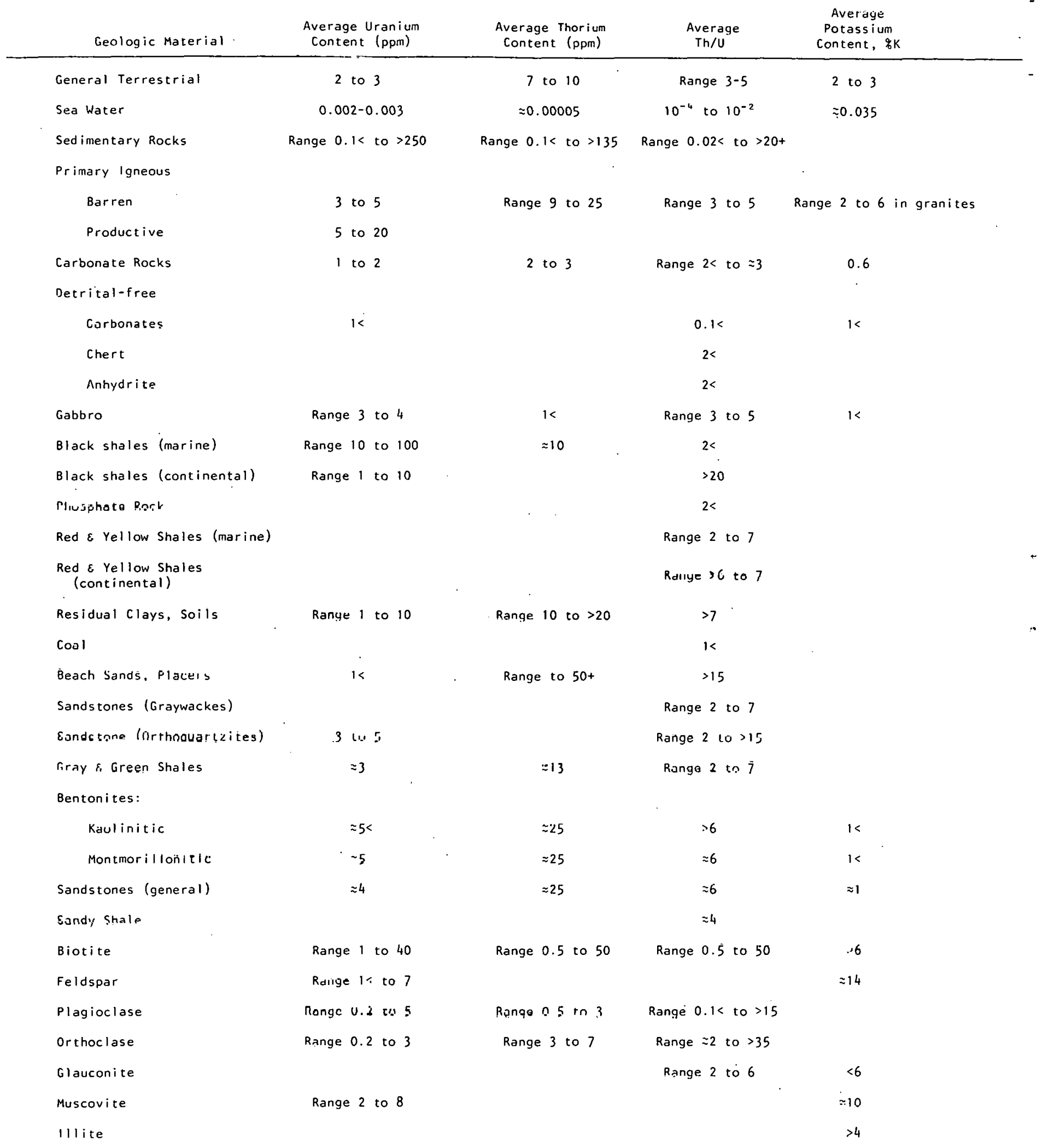


shale, ${ }^{40} \mathrm{~K}$ produces nearly half of the detected gamma-ray activity, the thorium series produces a little less than one-third, and the uranium series produces a little less than one-fourth. Gamma-ray logs run in "normal" shales should reflect these relative activities, and provide a means of detecting unusual mineralogical compositions in shales and argillaceous rocks.

2.) The mean uranium content of sandstone is about $4 \mathrm{ppm}$ and the "average" Th/U ratio is about 6 . The potassium curve is an excellent indicator of arkosic sandstones; many uranium deposits found in the United States occur in arkosic sandstones.

3.) The Th/U ratio can be useful in discriminating between those volcanic and plutonic rocks derived in part from sediments and those volcanics containing iron and uranium that have never been oxidized; the Th/U ratio in oxidized sediments can be expected to be much higher than the Th/U ratios in rocks that have never been oxidized (note that $\mathrm{Rb} / \mathrm{Sr}$ and ${ }^{87} \mathrm{Sr} /{ }^{86} \mathrm{Sr}$ ratio determinations and other methods are more definitive in this application).

4.) It may be possible to differentiate between marine red and yellow shales which have a low $T h / U$ ratio and continental red and yellow shales which have much higher ratios (6.0. or more). Using Th/U ratios, continental red shales can be differentiated from marine red shales, in some cases. Similarly, it is often possible to distinguish between low Th/U ratio marine black shales and high Th/U ratio continental black shales.

5.) Bentonites have an average Th/U ratio of about 6.0. The thorium content averages about $25 \mathrm{ppm}$ and the uranium content nearly $5.0 \mathrm{ppm}$. The Bentonites exhibit almost the full range of Th/U ratios found 
in sedimentary rocks, but only a few are lower than the intermediate range. Their thorium content averages about twice that of normal marine shales or igneous rocks; some samples have several times the Th concentration of common shales. Also, their average uranium content is nearly twice that of "normal" marine shales. It is the high thorium and uranium concentrations combined with a high potassium concentration that causes the high gamma-ray activity exhibited by Bentonites. Generally, Bentonites are easily detected on radiation logs.

6.) $K, U$, Th concentration and $T h / U$ ratio logs obtained with the gammaray spectrometer system offer numerous possibilities for improving subsurface interpretations, particularly in locating unconformities under which there are well-weathered fossil soils, in distinguishing between marine and continental shales, possibly in recognizing purous zones, dolomitized zones, and high-residue zones in limestones, and iil characterizing sedimentary sections for correlation, as previously suggested and illustrated in examples which follow. Using gamma-ray spectral logs, potassium contents offer other sets of ratio para" meters which aid in lithology identification.

Figure 20 illustrates some reconstructed gamma-ray spectral (Th/U) $\log$ responses in various rock types; the log was synthesized from average gammaray spectral measurements carried out on core samples from the general rock types described in the lithologic section of Figure 20 . When the Th/U ratios are combined with the $K, U$, and Th curve data, excellent lithology discrimination often is possible. 


\begin{tabular}{l} 
GENERALIZED \\
$\begin{array}{l}\text { STRATIGRAPHIC } \\
\text { SECTION }\end{array}$ \\
\begin{tabular}{|l|l|l|l|l|l|l|l|l|l|l|l|l|}
\hline GRAY SHALE & & & & & & & & \\
\hline
\end{tabular} \\
\hline LIMESTONE
\end{tabular}

Figurè 20

Reconstructed Lithology and Th/U Log Based on Average Gamma-Ray Spectrometer Measurements on Core Samples 
Two examples illustrate some of the kinds of data obtained from KUT logs:

Example 1. Figure 21 shows a gross gamma-ray $\log$ and a KUT log over the same interval in a borehole at Spor Mountain, Juab County, Utah. The increase in radioactivity on the gross gamma-ray curve from about $27.4 \mathrm{~m}(90 \mathrm{ft})$ to $33.5 \mathrm{~m}(110 \mathrm{ft})$ suggests that a $6 \mathrm{~m}(20 \mathrm{ft})$ mineralized zone is present in this interval. If the zone were assumed to contain low grade amounts of uranium, the zone could be expected to contribute to the economic potential of the deposit. However, the KUT log clearly shows that this anomaly is almost entirely caused by thorium, as defined by the increase in the thorlum channel in this interval. As a result of this KUT information, the zone was not included as a potential uranium source. The radioactive zones centered at $35 \mathrm{~m}$ $(115 \mathrm{ft})$ and $39.6 \mathrm{~m}(130 \mathrm{ft})$ on the gross gamma-ray curve, are shown by the KUT $\log$ to contain uranium.

Example 2. Figure 22 is a comparison between the rock types identified by core analysis and the KUT response characteristics of these rock types on the spectral log. From the upper part of the hole to a depth of $80 \mathrm{~m}$, the lithology of the formation surrounding the borehole consists of alternating diabase and granite zones. The potassium (K) curve on the KUT log reflects the higher potassium content of the granite compared to the diabase. Other diabase zones, selected from the KUT $\mathrm{log}$, occur from $375 \mathrm{~m}$ to $398 \mathrm{~m}$ and $417 \mathrm{~m}$ to $452 \mathrm{~m}$. The diabase zones also exhibit a low thorium concentration compared to the predominanlly granite zones. The response of the KUT probe to specific rock types within the igneous zone suggests that the KUT $\log$ can be of significant use in lithology definition (Callihan, 1976).

To date, these KUT systems have been successfully run in approximately 40,000 feet of borehole for uranium exploration and for uranium reserve determination. 

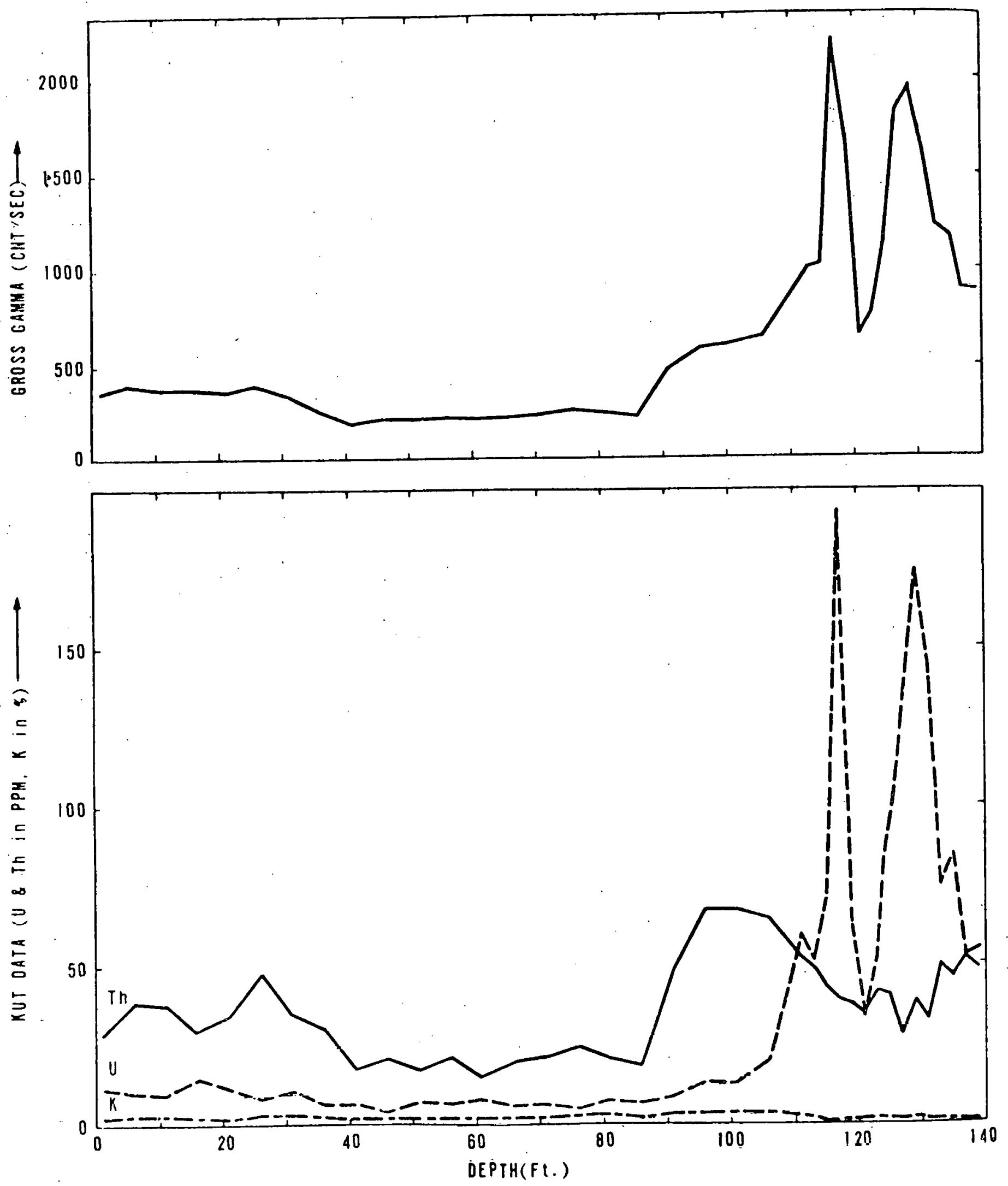

Figure 21

KUT Log Run in a Spor Mountain Hole in Juab County, Utah 


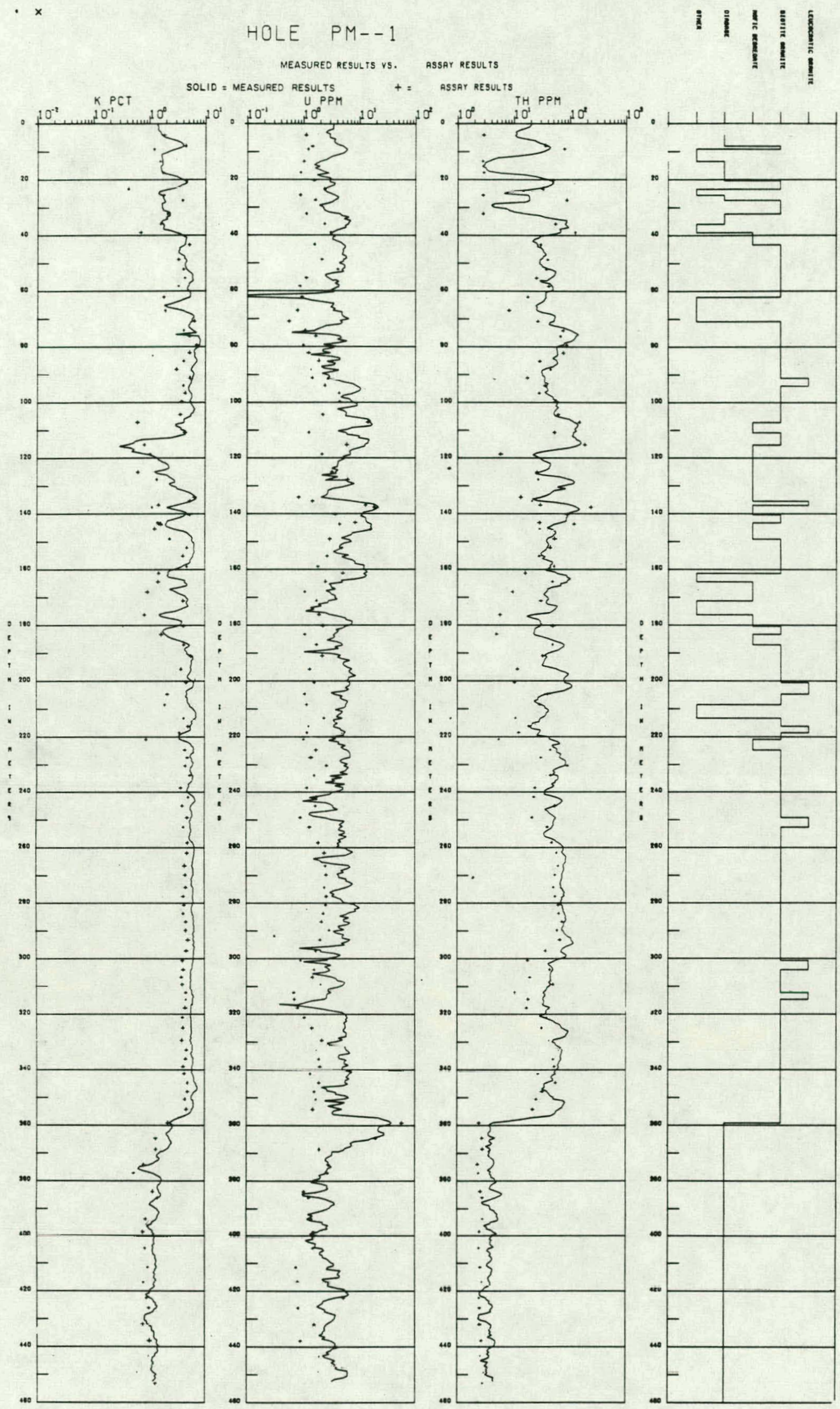

Figure 22

KUT Log from Pedro Mountain No. 1, Carbon County, Wyoming 


\section{CONCLUSIONS}

Gamma-ray spectral systems have been developed, field tested, and applied to uranium exploration and exploitation problems. The response of these gamma-ray spectral systems, in combination with other probe responses, can yield important information concerning subsurface rock types in "wildcat" exploration areas. For example, these log combinations can be used to aid in distinguishing between carbonates, evaporites, detritals, shales, coals, intrusives, extrusives, and other rock types. In addition, the ability to distinguish between marine and continental rocks is useful in establishing the depositional environment. Furthermore, an ability to determine gross color distinctions in shales, based on $K, U$, and Th concentrations and the resulting ratios, provides a method of relating rock units in a basin to relative distance from the shore line which existed during deposition. In an exploration sense, this approach defines the direction in which additional boreholes should be located.

Finally, variations in $K, U$, and Th concentrations resulting from gammaray spectal log evaluation can serve as proximity indicators in locating potential radioactive mineral accumulations.

\section{ACKNOWLEDGEMENTS}

We wish to thank the many individuals in DOE, particularly P.H. Dodd, and in BFEC, not listed as authors, who significantly contributed to the design, development, and testing of the gamma-ray spectra! (KUT) systems, and to the development of calibration techniques and evaluation methods. 


\section{SELECTED REFERENCES}

Adams, J.A.S. and C.E. Weaver, 1958, Thorium-to-Uranium Ratios as Indicators of Sedimentary Processes: Example of Concept of Geochemical Facies: American Association of Petroleum Geologists Bulletin, v. 42, p. 387-430. Callihan, M.C., 1976, Pedro Mountain No. 1, Eastern Granite Mountains, Carbon County, Wyoming: Internal Report No. BFEC-1976-9, Bendix Field Engineering Corporation, Grand Junction, Colorado.

Dodd, P.H. and D. H. Eschliman, 1971, Borehole Logging Techniques for Uranium Exploration and Evaluation: NATO Advanced Study Institute on Methods of Prospecting for Uranium Minerals, Sept. 21-0ct. 2, London, England.

Duray, J.R., 1976, A Brief Review of the Basis For, and the Procedures Currently Utilized In, Gross Gamma-Ray Log Calibration: Internal Report No. GJBX-61 (76), Bendix Field Engineering Corporation, Grand Junction, Colorado. Evans, Hilton B., 1967, Personal Communication Concerning the Application of Gamma-Ray Spectroscopy of Core Samples to Correlation Between Boreholes in units of the Phosphoria Formation.

Hurley, P.M., 1956, Direct Radiometric Measurement by Gamma-Ray Scintillometer: Bulletin of The Geological Soclety of Amerlcan, v. 67, p. 395-411.

Key, B.N. and D.H. Eschliman, 1974, Preliminary Evaluation of a Spectral Logging Method for the Borehole: Report No. GJ0-912-24, prepared for Resource Division, U.S. Atomic Energy Commission by Lucius Pitkin, Inc., Grand Junction, Colorado.

Kosanke, K.L.; M.C. Callihan, and C.D. Koch, 1975, Brief Discussion of the Importance of KUT Spectrographic Data in Both Surface and Subsurface Applications: Internal Report No. BFEC-1975-1, Bendix Field Engineering Corp., Grand Junction, Colorado.

Lock, G.A. and W.A. Hoyer, 1971, Natural Gamma-Ray Spectral Logging: The Log Analyst, Vol. XII, No. 5 . 
Marett, G.; P. Chevalier; P. Souhaite; and J. Suau, 1976, Shaly Sand Evaluation Using Gamma-Ray Spectrometry, Applied to the North Sea Jurasisic: Transactions, Society of Professional Well Log Analysts, Seventeenth Annual Logging Symposium, June 9-12, Denver, Colorado.

Salamon, B., 1976, The Present State of Scintillation Counting Technique in Nuclear Well Logging: The Log Analyst, Vol. XVII, No. 6.

Stromswold, D. C. and J. Meisner, 1978, Gamma-Ray Spectrum Stabilization In A Borehole Probe Using A Light Emitting Diode: paper presented at the 1978. IEEE Nuclear Science Symposium, October 18-20, Washington, D.C. Wichmann, P. A.; V. C. McWhi.rter; and C. E. Hopkinson, 1975, Field Results of the Natural Gamma-Ray Spectralog: Transactions, Society of Professional Well Log Analysts Sixteenth Annual Logging Symposium, June 4-7; New Orleans, Louisiana. 